\title{
Tintininos (Ciliophora, Tintinnina) de águas subtropicais na região Sueste-Sul do Brasil. I. Famílias Codonellidae, Codonellopsidae, Coxliellidae, Cyttarocylidae, Epiplocylidae, Petalotrichidae, Ptychocylidae, Tintinnididae e Undellidae ${ }^{1}$
}

\author{
Luciano Felício Fernandes ${ }^{2}$ \\ ${ }^{1}$ Contribuição número 1467 do Departamento de Zoologia, Universidade Federal do Paraná. \\ 2 Departamento de Botânica, Setor de Ciências Biológicas, Universidade Federal do Paraná. Centro Politécnico, Caixa Postal \\ 19031, 81531-980 Curitiba, Paraná, Brasil. E-mail: Iff@ufpr.br
}

\begin{abstract}
Tintinnids (Ciliophora, Tintinnina) from subtropical waters of the Southern Brazil. I. Families Codonellidae, Codonellopsidae, Coxliellidae, Cyttarocylidae, Epiplocylidae, Petalotrichidae, Ptychocylidae, Tintinnididae and Undellidae. A taxonomic survey on the tintinnids (Suborder Tintinnina) collected in subtropical waters of the Southern Brazil $\left(22^{\circ} \mathrm{S}-34^{\circ} \mathrm{S}\right)$ was carried out, based in different oceanographic cruises covering shelf and oceanic waters. Eighty nine species were recorded, and Amphorides amphora (Claparède 8 Lachmann, 1858) Strand, 1928, Dadayella ganimedes (Entz,1884) Kofoid \& Campbell,1929, Eutintinnus spp., Rhabdonellopsis apophysata (Cleve, 1900) Kofoid \& Campbell, 1929 , Tintinnopsis spp. (neritic waters) and Xystonellopsis spp. were abundant. For all of species descriptions, measurements and drawings, as well comments on the taxonomy and results on horizontal and vertical distributions on the water column were furnished. Some species showed preference by deep waters, like Epicancella nervosa (Cleve, 1900) Kofoid \& Campbell, 1929, Xystonellopsis spp., Salpingella spp. and Brandtiella palliata (Brandt,1906) Kofoid \& Campbell, 1929. In this work the families Codonellidae, Codonellopsidae, Coxliellidae, Cytarocyllidae, Epiplocylidae, Petalotrichidae, Ptychocylidae, Tintinnididae and Undellidae were studied. The other four families were covered in another work, also containing the discussion about biogeography and vertical distribution in the water column.

KEY WORDS. taxonomy, microzooplankton, Southwestern Atlantic Ocean, south Brazil.
\end{abstract}

RESUMO. Um levantamento taxonômico dos tintininos (Subordem Tintinnina) coletados em águas subtropicais do Sul do Brasil $\left(22^{\circ} \mathrm{S}-34^{\circ} \mathrm{S}\right)$ foi realizado, com base em diferentes cruzeiros oceanográficos abrangendo águas oceânicas e de plataforma. Oitenta e nove espécies foram registradas, e Amphorides amphora (Claparède \& Lachmann, 1858) Strand, 1928, Dadayella ganimedes (Entz, 1884) Kofoid \& Campbell, 1929, Eutintinnus spp., Rhabdonellopsis apophysata (Cleve, 1900) Kofoid \& Campbell, 1929, Tintinnopsis spp. (águas neríticas) e Xystonellopsis spp. foram abundantes. Para todas as espécies foram fornecidos descrições, medidas e desenhos, bem como comentários sobre taxonomia e resultados referentes às distribuiç̧ões horizontal e vertical na coluna de água. Algumas espécies mostraram preferência por águas profundas como Epicancella nervosa (Cleve, 1900) Kofoid \& Campbell, 1929, Xystonellopsis spp., Salpingella spp. e Brandtiella palliata (Brandt, 1906) Kofoid \& Campbell, 1929. Neste trabalho foram estudas as Famílias Codonellidae, Codonellopsidae, Coxliellidae, Cytarocyllidae, Epiplocylidae, Petalotrichidae, Ptychocylidae, Tintinnididae e Undellidae. As outras quatro famílias foram cobertas em outro trabalho, também contendo a discussão sobre biogeografia e distribuição vertical na coluna de água.

PALAVRAS CHAVE. Microzooplâncton, Oceano Attântico Sul Ocidental, sul do Brasil, taxonomia.

Os ciliados da Subordem Tintinnina constituem um importante grupo do microplâncton marinho, atuando como agentes intermediários nos fluxos de matéria orgânica na alça microbiana, pois se alimentam de bactérias e nanoflagelados $(0,2-20,0 \mu \mathrm{m})$, classes de tamanho geralmente não capturadas por predadores de maior porte, como copépodos e outros crustáceos (Lynn \& Montagnes 1991, Pierce \& Turner 1992, Bernard \& RAsSOUlzadegan 1993). Estes protozoários também removem quantidades significativas da biomassa algal em virtude de seu rápido crescimento e elevada taxa metabólica (SHERR et al. 1986, Stoecker \& Capuzzo 1990, Garrison \& Gowing 1993).

Várias espécies são indicadoras importantes de massas de água ou de áreas de ressurgência devido a suas características estenóicas ou suas preferências por águas profundas, como espécies dos gêneros Amplectella Kofoid \& Campbell, 1929, Brandtiella Kofoid \& Campbell, 1929, Cyttarocylis Kofoid \& 
Campbell, 1929 emend. Kofoid \& Campbell, 1939, Rhabdonellopsis Kofoid \& Campbell, 1929 e Xystonellopsis Jörgensen, 1924 para águas subtropicais e tropicais; e Amphorides Strand, 1928, Codonellopsis Jörgensen, 1899, Cymatocylis Laackmann, 1910 e Laackmaniella Jörgensen, 1927 para águas subantárticas e antárticas (Balech 1972, Souto 1981, Uribe \& Castillo 1982, Pierce \& Turner 1993, Fernandes 1999). Como citado por Thompson et al. (1999), os tintininos apresentam importantes vantagens como indicadores biológicos em relação a outros grupos do zoplâncton como radiolários e foraminíferos, pois são mais abundantes, com maiores taxas de reprodução e habitam áreas costeiras e oceânicas, enquanto outros grupos são restritos às oceânicas.

Alguns problemas relacionados à taxonomia do grupo residem na morfologia bastante variável da lórica dentro de muitos gêneros, em virtude não somente de sua susceptibilidade às variações ambientais, como também do polimorfismo decorrente das diferentes fases do ciclo vital do ciliado (LavaL-Peuto 1981, 1982, Laval-Peuto \& Browlee 1986, Alder 1999). Mesmo assim, não se pode negar a praticidade das determinações proporcionada pelas características da lórica, devido a sua facilidade de preservação em campo e resistência prolongada em fixadores. Obviamente, a ampliação dos estudos baseados na disposição da ciliatura, núcleos e outras características citológicas auxiliará significativamente para a melhoria da sistemática e filogenia da Subordem Tintinnina, como os realizados por SNYDER \& Browlee (1991), SNIEZeCK et al. (1991) e Chor et al. (1992).

Souto (1981) realizou uma revisão dos tintininos do Oceano Atlântico Sul-Ocidental, fornecendo dados sobre a distribuição, morfologia e biometria da lórica das espécies. Infelizmente, os desenhos das espécies são bastante preliminares, e apenas medidas de comprimento (algumas poucas de diâmetro oral) foram consideradas, embora esta última seja essencial para determinação e intercomparação das espécies (KoFoID \& Campbell 1929, Balech 1959). Posteriormente, Alder (1999) realizou a revisão mais completa até o momento para a região mencionada, também completando as imperfeições do trabalho de Souto (1981) com figuras originais ou extraídas da literatura, chaves de identificação para gêneros, dados biogeográficos, revisão nomenclatural e características diacríticas de algumas espécies (embora sem medidas das lóricas!). Pierce \& TURNER (1992) revisaram a distribuição geográfica mundial de alguns gêneros de tintininos, incluindo espécies de gêneros ocorrentes em águas brasileiras, como Helicostomella Jörgensen, 1924, Petalotricha Kent emend. Daday emend. Brandt, 1907, Rhabdonellopsis e Tintinnopsis Stein, 1867.

Poucos trabalhos taxonômicos foram realizados na região Sueste-Sul brasileira e, geralmente, fornecem citações superficiais sobre este importante grupo de ciliados (Bresslau 1906, Faria \& Cunha 1917, Cunha \& Fonseca 1918, Sassi et al. 1999). Apenas os trabalhos de Souto $(1970,1970 a)$ abordaram com maior profundidade sua taxonomia e distribuição em águas da plataforma do sul do Brasil até o litoral do Rio de Janeiro $\left(33^{\circ} \mathrm{S}-22^{\circ} \mathrm{S}\right)$. O trabalho revisional de Alder (1999) preencheu várias lacunas para a taxonomia dos tintininos no Oceano Atlântico Sul-ocidental, mas a área em questão foi insuficientemente amostrada. Recentemente, THOMpson et al. (1999) realizaram um importante estudo sobre a biogeografia e biomassa de tintininos abrangendo desde a área transicional representada pela Zona de Confluência Brasil-Malvinas até águas antárticas, entre $34^{\circ} \mathrm{S}$ e $58^{\circ} \mathrm{S}$.

A partir da análise dos estudos anteriores mencionados acima, ficou explícita a necessidade ainda premente de investigações sobre estes ciliados no Oceano Atlântico Sul-Ocidental, especialmente nas águas brasileiras. Portanto, uma série de trabalhos destinados à estudar a taxonomia, biogeografia e biomassa dos tintininos no Oceano Atlântico Sul-Ocidental está sendo realizada (Fernandes 1999, 2004, Fernandes \& BRANDini 1999), com base na análise de amostras coletadas em águas subtropicais, subantárticas e antárticas em diferentes cruzeiros oceanográficos promovidos pela Marinha do Brasil e Instituto Oceanográfico da Universidade de São Paulo (IO/USP). É importante ressaltar que expedições deste tipo são extremamente dispendiosas e necessitando de logística volumosa, aumentando a relevância do material biológico coletado e da análise do mesmo.

No presente trabalho foi realizado um estudo taxonômico das espécies encontradas em águas subtropicais coletadas na plataforma e área oceânica da região Sueste-Sul do Brasil durante as Operações Sueste IV e Monitor IV, a Operação Antártica XI do Programa Antártico Brasileiro (PROANTAR XI), promovidas pela Marinha do Brasil; e do Projeto Circulação Oceânica na Região Oeste do Atlântico Sul (COROAS), promovido pelo Instituto Oceanográfico da Universidade de São Paulo. São fornecidas as descrições, medidas, desenhos e fotomicrografias das espécies, bem como comentários sobre a distribuição geográfica dos táxons determinados para as famílias Codonellidae, Codonellopsidae, Coxliellidae, Cytarocyllidae, Epiplocylidae, Petalotrichidae, Ptychocylidae, Tintinnididae e Undellidae. As famílias Dictyocystidae, Rhabdonellidae, Tintinnidae e Xystonellidae e a discussão conjunta de todas as famílias estão contempladas em outro trabalho (FERNANDEs 2004).

\section{MATERIAL E MÉTODOS}

O material analisado é proveniente de duas operações oceanográficas realizadas pelo Navio Oceanográfico "Almirante Saldanha" da Marinha do Brasil/Diretoria de Hidrografia e Navegação na região Sueste-Sul do Brasil, uma expedição na primeira fase do XI Programa Antártico Brasileiro (PROANTAR XI), a bordo do NApOc. "Barão de Teffé" e um cruzeiro oceanográfico realizado pelo Noc. W. Besnard do Instituto Oceanográfico da Universidade de São Paulo. As amostras foram obtidas em profundidades variáveis e épocas diferentes. As características de cada coleção são descritas a seguir, e as coordenadas geográficas das estações, dados físicos e químicos e de clorofila-a são fornecidos no Apêndice (Tabs I e II).

Na Operação Sueste IV, realizada de 21 a 27 de outubro de 1984 , a área amostrada localizou-se entre $27^{\circ} 06^{\prime} \mathrm{S}-29^{\circ} 38^{\prime} \mathrm{S}$ e $46^{\circ} 18^{\prime} \mathrm{W}-46^{\circ} 45^{\prime} \mathrm{W}$, abrangendo águas neríticas, de plataforma 
Tintininos de águas subtropicais. I. Famílias Codonellidae, Codonellopsidae...

Tabela I. Dados das estações amostradas durante as Operações Sueste IV (outubro de 1984) e Monitor IV* (12-22 de março de 1989). Valores de temperatura e salinidade tomados da profundidade de $10 \mathrm{~m}$.

\begin{tabular}{|c|c|c|c|c|c|c|c|c|c|c|c|c|}
\hline \multicolumn{8}{|c|}{ Operação Sueste IV } & \multicolumn{5}{|c|}{ Operação Monitor IV* } \\
\hline Estação & $\begin{array}{l}\text { Latitude } \\
\text { Sul }\end{array}$ & $\begin{array}{l}\text { Longitude } \\
\text { Oeste }\end{array}$ & Data & $\begin{array}{l}\text { Profundidade } \\
(\mathrm{m})\end{array}$ & $\begin{array}{c}\text { Temp. } \\
\left({ }^{\circ} \mathrm{C}\right)\end{array}$ & $\begin{array}{l}\text { Salinidade } \\
\text { (\%o) }\end{array}$ & $\begin{array}{l}\text { Clr-a } \\
(\mu \mathrm{g} / \mathrm{l})\end{array}$ & Estação & $\begin{array}{l}\text { Latitude } \\
\text { Sul }\end{array}$ & $\begin{array}{l}\text { Longitude } \\
\text { Oeste }\end{array}$ & $\begin{array}{c}\text { Temp. } \\
\left({ }^{\circ} \mathrm{C}\right)\end{array}$ & $\begin{array}{c}\text { Salinidade } \\
(\% 0)\end{array}$ \\
\hline 6596 & $28^{\circ} 26^{\prime}$ & $48^{\circ} 35^{\prime}$ & $22 / 10 / 85$ & 52 & 21,00 & 34,66 & 0,32 & 1 & $23^{\circ} 45^{\prime}$ & $43^{\circ} 10^{\prime}$ & 26,6 & 36,96 \\
\hline 6597 & $28^{\circ} 38^{\prime}$ & $48^{\circ} 45^{\prime}$ & $23 / 10 / 85$ & 61 & 19,31 & 35,02 & 2,17 & 2 & $24^{\circ} 05^{\prime}$ & $43^{\circ} 01^{\prime}$ & 27,8 & 37,50 \\
\hline 6598 & $28^{\circ} 49^{\prime}$ & $48^{\circ} 22^{\prime}$ & $23 / 10 / 85$ & 108 & 20,80 & 34,96 & 0,30 & 3 & $24^{\circ} 20^{\prime}$ & $42^{\circ} 30^{\prime}$ & 27,9 & 37,50 \\
\hline 6599 & $29^{\circ} 06^{\prime}$ & $47^{\circ} 51^{\prime}$ & $23 / 10 / 85$ & 418 & 21,40 & 35,83 & 0,25 & 4 & $24^{\circ} 50^{\prime}$ & $41^{\circ} 58^{\prime}$ & 27,2 & 36,94 \\
\hline 6600 & $29^{\circ} 22^{\prime}$ & $47^{\circ} 25^{\prime}$ & $23 / 10 / 85$ & 1190 & 21,46 & 35,94 & 0,22 & 5 & $25^{\circ} 00^{\prime}$ & $41^{\circ} 30^{\prime}$ & 26,8 & 36,85 \\
\hline 6601 & $29^{\circ} 38^{\prime}$ & $46^{\circ} 53^{\prime}$ & $24 / 10 / 85$ & 1800 & 22,08 & 36,58 & 0,29 & 6 & $25^{\circ} 25^{\prime}$ & $41^{\circ} 08^{\prime}$ & 26,6 & 36,82 \\
\hline 6602 & $29^{\circ} 16^{\prime}$ & $46^{\circ} 32^{\prime}$ & $24 / 10 / 85$ & 2100 & 21,38 & 36,81 & 0,22 & 7 & $25^{\circ} 40^{\prime}$ & $40^{\circ} 40^{\prime}$ & 26,4 & 36,67 \\
\hline 6603 & $29^{\circ} 03^{\prime}$ & $47^{\circ} 02^{\prime}$ & $24 / 10 / 85$ & 1140 & 22,55 & 36,78 & 0,09 & 8 & $26^{\circ} 00^{\prime}$ & $40^{\circ} 10^{\prime}$ & 26,8 & 36,91 \\
\hline 6604 & $28^{\circ} 46^{\prime}$ & $47^{\circ} 27^{\prime}$ & $25 / 10 / 85$ & 552 & 21,43 & 35,45 & 0,22 & 9 & $26^{\circ} 12^{\prime}$ & $39^{\circ} 38^{\prime}$ & 26,9 & 36,86 \\
\hline 6605 & $28^{\circ} 36^{\prime}$ & $47^{\circ} 50^{\prime}$ & $25 / 10 / 85$ & 136 & 21,58 & 35,64 & 0,15 & 10 & $32^{\circ} 35^{\prime}$ & $41^{\circ} 55^{\prime}$ & 27,6 & 37,08 \\
\hline 6606 & $28^{\circ} 24^{\prime}$ & $48^{\circ} 09^{\prime}$ & $25 / 10 / 85$ & 98 & 21,53 & 35,61 & 0,34 & 11 & $24^{\circ} 03^{\prime}$ & $41^{\circ} 22^{\prime}$ & 27,3 & 37,12 \\
\hline 6607 & $28^{\circ} 13^{\prime}$ & $48^{\circ} 30^{\prime}$ & $25 / 10 / 85$ & 58 & 21,02 & 34,69 & 0,42 & 12 & $24^{\circ} 23^{\prime}$ & $40^{\circ} 58^{\prime}$ & 28,1 & 37,38 \\
\hline 6608 & $28^{\circ} 00^{\prime}$ & $48^{\circ} 24^{\prime}$ & $25 / 10 / 85$ & 63 & 21,00 & 34,76 & 0,75 & 13 & $24^{\circ} 46^{\prime}$ & $40^{\circ} 30^{\prime}$ & 27,7 & 37,16 \\
\hline 6609 & $27^{\circ} 46^{\prime}$ & $48^{\circ} 19^{\prime}$ & $25 / 10 / 85$ & 52 & 21,08 & 34,35 & 1,06 & 14 & $25^{\circ} 02^{\prime}$ & $39^{\circ} 57^{\prime}$ & 27,1 & 36,89 \\
\hline 6610 & $27^{\circ} 34^{\prime}$ & $48^{\circ} 05^{\prime}$ & $26 / 10 / 85$ & 85 & 21,63 & 35,20 & 0,15 & 15 & $25^{\circ} 15^{\prime}$ & $39^{\circ} 26^{\prime}$ & 27,0 & 36,74 \\
\hline 6611 & $28^{\circ} 09^{\prime}$ & $47^{\circ} 30^{\prime}$ & $26 / 10 / 85$ & 130 & 21,72 & 35,41 & 0,13 & 16 & $25^{\circ} 30^{\prime}$ & $39^{\circ} 00^{\prime}$ & 26,8 & 36,64 \\
\hline 6612 & $28^{\circ} 21^{\prime}$ & $47^{\circ} 11^{\prime}$ & $26 / 10 / 85$ & 320 & 22,42 & 36,62 & 0,16 & 17 & $25^{\circ} 55^{\prime}$ & $38^{\circ} 45^{\prime}$ & 26,9 & 36,80 \\
\hline 6613 & $28^{\circ} 37^{\prime}$ & $46^{\circ} 44^{\prime}$ & $26 / 10 / 85$ & 1060 & 22,22 & 36,80 & 0,08 & 18 & $26^{\circ} 08^{\prime}$ & $38^{\circ} 06^{\prime}$ & 26,3 & 36,43 \\
\hline 6614 & $28^{\circ} 50^{\prime}$ & $46^{\circ} 10^{\prime}$ & $26 / 10 / 85$ & 3200 & 21,32 & 36,50 & 0,13 & 19 & $23^{\circ} 07^{\prime}$ & $40^{\circ} 54^{\prime}$ & 26,9 & 37,08 \\
\hline 6615 & $28^{\circ} 21^{\prime}$ & $46^{\circ} 19^{\prime}$ & $27 / 10 / 85$ & 3440 & 22,08 & 36,73 & 0,15 & 20 & $23^{\circ} 16^{\prime}$ & $40^{\circ} 18^{\prime}$ & 27,9 & 37,33 \\
\hline 6616 & $28^{\circ} 05^{\prime}$ & $46^{\circ} 46^{\prime}$ & $27 / 10 / 85$ & 1120 & 22,56 & 36,80 & 0,16 & 21 & $23^{\circ} 40^{\prime}$ & $39^{\circ} 58^{\prime}$ & 28,2 & 37,41 \\
\hline 6617 & $27^{\circ} 51^{\prime}$ & $47^{\circ} 16^{\prime}$ & $27 / 10 / 85$ & 438 & 22,19 & 36,47 & 0,11 & 22 & $24^{\circ} 00^{\prime}$ & $39^{\circ} 42^{\prime}$ & 27,5 & 37,00 \\
\hline 6618 & $27^{\circ} 39^{\prime}$ & $47^{\circ} 37^{\prime}$ & $27 / 10 / 85$ & 186 & 22,22 & 36,43 & 0,21 & 23 & $24^{\circ} 10^{\prime}$ & $39^{\circ} 15^{\prime}$ & 26,9 & 36,69 \\
\hline 6619 & $27^{\circ} 30^{\prime}$ & $47^{\circ} 57^{\prime}$ & $27 / 10 / 85$ & 91 & 21,95 & 35,78 & 0,29 & 24 & $24^{\circ} 32^{\prime}$ & $38^{\circ} 51$ & 27,0 & 36,66 \\
\hline 6620 & $27^{\circ} 22^{\prime}$ & $48^{\circ} 16^{\prime}$ & $28 / 10 / 85$ & 43 & 21,84 & 34,97 & 0,41 & 25 & $24^{\circ} 50^{\prime}$ & $38^{\circ} 30^{\prime}$ & 27,2 & 36,65 \\
\hline 6621 & $27^{\circ} 05^{\prime}$ & $48^{\circ} 16^{\prime}$ & $28 / 10 / 85$ & 35 & 21,70 & 34,86 & 0,36 & 26 & $25^{\circ} 15^{\prime}$ & $38^{\circ} 02^{\prime}$ & 27,4 & 36,79 \\
\hline
\end{tabular}

${ }^{*}$ ) As estações cobriram áreas com profundidades entre 2304 e $3950 \mathrm{~m}$.

e oceânicas do Estado de Santa Catarina (DHn 1987). O "grid" amostral foi constituído por 26 estações oceanográficas distanciadas 30 milhas náuticas entre si. Em cada estação foi realizado arrasto vertical com rede de plâncton de $25 \mu \mathrm{m}$ de abertura da malha, de $100 \mathrm{~m}$ à superfície, ou do fundo à superfície em estações com profundidade inferior a $100 \mathrm{~m}$. O material retido foi preservado com formaldeído $2 \%$ e dividido em subamostras para melhor observação em microscopia óptica. Amostras de água para análise de parâmetros físicos e químicos foram coletadas com garrafa de Nansen. Valores de temperatura foram obtidos com termômetros de inversão e salinidade com salinômetro Grundy. As concentrações de clorofila-a foram estimadas a partir de leituras em espectrofotômetro após extração com acetona (90\%), de acordo com STRICKLAND \& Parsons (1972) e equações de Jeffrey \& Humphrey (1975).

A Operação Monitor IV foi desenvolvida de 12 a 22 de março de 1989, e abrangeu as águas oceânicas ao largo do Estado do Rio de Janeiro, entre $22^{\circ} \mathrm{S}-26^{\circ} \mathrm{S}$ e $39^{\circ} \mathrm{W}-43^{\circ} \mathrm{W}$, formando um "grid" amostral de 27 estações oceanográficas distanciadas 30 milhas náuticas entre si (DHN 1989). As estações cobriram áreas com profundidades entre 2304 e $3950 \mathrm{~m}$. Em cada estação foram coletadas amostras de água de superfície, 10 e 100 m, utilizando-se garrafa de Van Dorn, e separando-se $5000 \mathrm{ml}$ de cada para análise do plâncton, imediatamente preservada com formaldeído até a concentração final de $1 \%$. Um total de 81 amostras foi obtido para análise. Este material foi sedimentado por sete dias em provetas e concentrado até o volume de $50 \mathrm{ml}$, retirando-se o excesso por sifonamento. As técnicas utilizadas para obtenção de valores de temperatura e salinidade foram as mesmas descritas acima para a Op. Sueste IV. Apenas as amostras nas quais ocorreram tintininos foram mencionadas nos resultados. 
Tabela II. Dados das estações amostradas durante o PROANTAR XI (novembro de 1992), e Projeto COROAS* (verão de 1994). Os valores de temperatura e salinidade indicados para o Proj. COROAS referem-se ao intervalo de temperatura ao longo do arrasto vertical estratificado.

\begin{tabular}{|c|c|c|c|c|c|c|c|c|c|c|c|c|c|c|}
\hline \multicolumn{8}{|c|}{ PROANTAR XI (novembro de 1992) } & \multicolumn{7}{|c|}{ Projeto COROAS* (verão de 1994)* } \\
\hline Estação & $\begin{array}{l}\text { Lat. } \\
\text { Sul }\end{array}$ & $\begin{array}{l}\text { Long. } \\
\text { Oeste }\end{array}$ & Data & $\begin{array}{l}\text { Prof. } \\
(\mathrm{m})\end{array}$ & $\begin{array}{c}\text { Temp. } \\
\left({ }^{\circ} \mathrm{C}\right) \\
\end{array}$ & $\begin{array}{l}\text { Clr.-a } \\
(\mu \mathrm{g} / \mathrm{l})\end{array}$ & $\begin{array}{l}\text { Tint. } \\
\text { (Ind./I) }\end{array}$ & Estação & Amostra & $\begin{array}{c}\text { Profund. } \\
(\mathrm{m})\end{array}$ & $\begin{array}{l}\text { Lat. } \\
\text { Sul }\end{array}$ & $\begin{array}{l}\text { Long. } \\
\text { Oeste }\end{array}$ & $\begin{array}{c}\text { Temp. } \\
\left({ }^{\circ} \mathrm{C}\right) \\
\end{array}$ & $\begin{array}{c}\text { Salinidade } \\
(\%)\end{array}$ \\
\hline 1 & $25^{\circ} 33^{\prime}$ & $45^{\circ} 16^{\prime}$ & $10 / 11 / 92$ & 163,0 & 23,0 & 0,22 & 6,7 & 8 & 1 & $0-200$ & $26^{\circ} 51^{\prime}$ & $43^{\circ} 04^{\prime}$ & $16,6-25,7$ & $35,7-36,6$ \\
\hline 2 & $25^{\circ} 59^{\prime}$ & $45^{\circ} 30^{\prime}$ & $10 / 11 / 92$ & 235,0 & 23,9 & 0,11 & 5,2 & 10 & 2 & $100-150$ & $28^{\circ} 03^{\prime}$ & $41^{\circ} 40^{\prime}$ & $19,7-24,3$ & $35,9-36,2$ \\
\hline 3 & $26^{\circ} 10^{\prime}$ & $45^{\circ} 42^{\prime}$ & $10 / 11 / 92$ & 338,0 & 24,2 & & 5,7 & 10 & 3 & $0-50$ & $28^{\circ} 03^{\prime}$ & $41^{\circ} 40^{\prime}$ & $24,3-25,4$ & 36,5 \\
\hline 4 & $26^{\circ} 24^{\prime}$ & $45^{\circ} 58^{\prime}$ & $10 / 11 / 92$ & 556,0 & 25,0 & 0,15 & 6,0 & 12 & 4 & $100-150$ & $28^{\circ} 57^{\prime}$ & $40^{\circ} 37^{\prime}$ & $17,3-18,5$ & $35,8-36,0$ \\
\hline 5 & $26^{\circ} 50^{\prime}$ & $46^{\circ} 20^{\prime}$ & $10 / 11 / 92$ & 475,0 & 25,0 & 0,18 & 7,1 & 12 & 5 & $0-50$ & $28^{\circ} 57^{\prime}$ & $40^{\circ} 37^{\prime}$ & $21,5-25,4$ & $36,2-36,5$ \\
\hline 6 & $27^{\circ} 16^{\prime}$ & $46^{\circ} 42^{\prime}$ & $10 / 11 / 92$ & 847,0 & 24,0 & & 17,3 & 14 & 6 & $0-50$ & $29^{\circ} 33^{\prime}$ & $39^{\circ} 55^{\prime}$ & $21,5-24,3$ & $35,9-36,2$ \\
\hline 7 & $28^{\circ} 09^{\prime}$ & $47^{\circ} 26^{\prime}$ & $11 / 11 / 92$ & 174,0 & 23,0 & 0,12 & 16,4 & 14 & 7 & $100-150$ & $29^{\circ} 33^{\prime}$ & $39^{\circ} 55^{\prime}$ & $16,4-17,6$ & $35,8-35,9$ \\
\hline 8 & $28^{\circ} 28^{\prime}$ & $47^{\circ} 45^{\prime}$ & $11 / 11 / 92$ & 145,0 & 22,5 & 0,20 & 14,3 & 23 & 8 & $0-50$ & $30^{\circ} 45^{\prime}$ & $41^{\circ} 56^{\prime}$ & $24,2-24,8$ & $36,3-36,7$ \\
\hline 9 & $28^{\circ} 50^{\prime}$ & $48^{\circ} 05^{\prime}$ & $11 / 11 / 92$ & 131,7 & 22,5 & 0,25 & 47,1 & 23 & 9 & $100-150$ & $30^{\circ} 45^{\prime}$ & $41^{\circ} 56^{\prime}$ & $17,4-19,7$ & $35,9-36,2$ \\
\hline 10 & $29^{\circ} 12^{\prime}$ & $48^{\circ} 25^{\prime}$ & $11 / 11 / 92$ & 128,0 & 23,0 & 0,34 & 15,5 & 25 & 10 & $0-50$ & $30^{\circ} 45^{\prime}$ & $44^{\circ} 52^{\prime}$ & $24,9-25,2$ & $36,1-36,3$ \\
\hline 11 & $29^{\circ} 33^{\prime}$ & $48^{\circ} 46^{\prime}$ & $11 / 11 / 92$ & 120,0 & 23,5 & 0,32 & 62,1 & 25 & 11 & $100-150$ & $30^{\circ} 45^{\prime}$ & $44^{\circ} 52^{\prime}$ & $17,5-19,9$ & $35,9-36,1$ \\
\hline 12 & $29^{\circ} 55^{\prime}$ & $49^{\circ} 07^{\prime}$ & $11 / 11 / 92$ & 107,2 & 22,5 & 0,21 & 30,5 & 26 & 12 & $0-50$ & $?$ & $?$ & $21,8-24,5$ & $35,8-36,1$ \\
\hline 13 & $30^{\circ} 16^{\prime}$ & $49^{\circ} 28^{\prime}$ & $11 / 11 / 92$ & 89,0 & 21,0 & 0,16 & 9,7 & 26 & 13 & $100-150$ & $?$ & $?$ & $16,7-17,5$ & $35,8-35,9$ \\
\hline 14 & $30^{\circ} 56^{\prime}$ & $50^{\circ} 09^{\prime}$ & $12 / 11 / 92$ & 87,8 & 21,0 & & 8,5 & 30 & 14 & $0-50$ & $?$ & $?$ & $24,7-25,1$ & $35,8-36,5$ \\
\hline 15 & $31^{\circ} 16^{\prime}$ & $50^{\circ} 30^{\prime}$ & $12 / 11 / 92$ & 78,2 & 19,5 & 0,24 & 18,6 & 30 & 15 & $100-150$ & $?$ & $?$ & $16,5-20,1$ & $35,7-36,2$ \\
\hline 16 & $31^{\circ} 35^{\prime}$ & $50^{\circ} 54^{\prime}$ & $12 / 11 / 92$ & 47,0 & 22,0 & & 45,5 & 38 & 16 & $0-40$ & $30^{\circ} 7^{\prime}$ & $48^{\circ} 58^{\prime}$ & $23,0-25,2$ & $35,3-36,5$ \\
\hline 17 & $31^{\circ} 53^{\prime}$ & $51^{\circ} 19^{\prime}$ & $12 / 11 / 92$ & 27,8 & 23,7 & & 4,0 & 38 & 17 & $100-130$ & $30^{\circ} 7^{\prime}$ & $48^{\circ} 58^{\prime}$ & $16,5-16,5$ & $35,6-35,7$ \\
\hline 18 & $32^{\circ} 07^{\prime}$ & $51^{\circ} 46^{\prime}$ & $12 / 11 / 92$ & 20,1 & 22,5 & 0,32 & 103,0 & 61 & 18 & $0-10$ & $25^{\circ} 20^{\prime}$ & $45^{\circ} 12^{\prime}$ & $25,2-25,2$ & 35,6 \\
\hline 19 & $33^{\circ} 01^{\prime}$ & $51^{\circ} 56^{\prime}$ & $15 / 11 / 92$ & 34,0 & 21,0 & 0,84 & 176,0 & 61 & 19 & $70-130$ & $25^{\circ} 20^{\prime}$ & $45^{\circ} 12^{\prime}$ & $13,5-15,8$ & $35,3-35,5$ \\
\hline 20 & $33^{\circ} 19^{\prime}$ & $51^{\circ} 54^{\prime}$ & $15 / 11 / 92$ & 57,0 & 19,0 & 0,35 & 56,9 & & & & & & & \\
\hline 21 & $33^{\circ} 35^{\prime}$ & $51^{\circ} 51^{\prime}$ & $15 / 11 / 92$ & 75,4 & 18,0 & 0,48 & 37,9 & & & & & & & \\
\hline 22 & $34^{\circ} 17^{\prime}$ & $51^{\circ} 50^{\prime}$ & $16 / 11 / 92$ & 118,2 & 18,0 & & 14,8 & & & & & & & \\
\hline 23 & $34^{\circ} 32^{\prime}$ & $51^{\circ} 56^{\prime}$ & $16 / 11 / 92$ & 148,2 & 17,5 & 0,28 & 44,4 & & & & & & & \\
\hline 24 & $34^{\circ} 40^{\prime}$ & $52^{\circ} 00^{\prime}$ & $16 / 11 / 92$ & 172,5 & 16,5 & 0,62 & 62,7 & & & & & & & \\
\hline 25 & $34^{\circ} 50^{\prime}$ & $52^{\circ} 04^{\prime}$ & $16 / 11 / 92$ & 220,1 & 15,5 & 0,18 & 39,0 & & & & & & & \\
\hline
\end{tabular}

*: As estações cobriram áreas com profundidades superiores a $1.000 \mathrm{~m}$. As concentrações de clorofila-a variaram de 0,01 a 0,33 $\mu \mathrm{g} / \mathrm{l}$.

Durante a primeira fase da Operação Antártica XI do Programa Antártico Brasileiro (PROANTAR XI) foram coletadas amostras de água de superfície a bordo do Navio da Marinha NaApOc "Barão de Teffé" entre 10 e 16 de novembro de 1992, ao longo de um transecto entre São Paulo (25 $33^{\prime}$ 'S) e Rio Grande do Sul ( $\left.34^{\circ} 50^{\prime} \mathrm{S}\right)$ e entre $45^{\circ} \mathrm{W}$ e $52^{\circ} \mathrm{W}$, com profundidades variando entre 20 e $800 \mathrm{~m}$. Vinte e cinco amostras de superfície para análise dos tintininos foram obtidas através da filtração reversa (Dodson \& THOMAs 1978) de 9-20 litros de água do mar em rede de $10 \mu \mathrm{m}$. Cada amostra foi concentrada para um volume de $200 \mathrm{ml}$ e preservada com formaldeído (2\%) neutralizado com borato de sódio. Em seguida, o filtrado resultante foi decantado e o sobrenadante sifonado, permanecendo um volume final de $50 \mathrm{ml}$.

Durante o cruzeiro de verão de 1994 do Projeto COROAS, abrangendo águas de plataforma e oceânicas do sul do Bra- sil entre $25^{\circ} \mathrm{S}-37^{\circ} \mathrm{S}$ e $49^{\circ} \mathrm{W}-39^{\circ} \mathrm{W}$, num total de 10 estações oceanográficas, foram realizados arrastos verticais estratificados com redes de estrangulamento ( $25 \mu \mathrm{m}$ de abertura das malhas) em diferentes níveis de profundidade, ou de $200 \mathrm{~m}$ à superfície, totalizando 19 amostras.

No laboratório, as amostras resultantes destes cruzeiros oceanográficos foram observadas em microscópio invertido Olympus IX 70 para determinação, biometria e descrição das espécies. Este método não deforma a lórica dos tintininos, evitando erros na mensuração dos indivíduos. A utilização de Rosa de Bengala para corar os ciliados facilitou a localização de espécies de lórica muito delicada ou pequena. Os desenhos (a partir de câmara clara) e fotomicrografias foram realizados a partir do microscópio invertido ou em microscópio Nikon Optphot, utilizando-se uma câmara de sedimentação de Kolkwitz $(0,5 / 1,0 \mathrm{ml})$ como meio de montagem. Os termos 
abundante ( $>20$ células), comum (5-20 células) e raro $(<5$ células) citados no texto referem-se aos resultados de contagem direta dos indivíduos na amostra e, portanto, têm valor apenas comparativo. $\mathrm{O}$ enquadramento taxonômico até o nível de Subordem baseou-se no sistema de Levine et al. (1980), e a separação em famílias em KoFord \& CAMPBelL (1939), as quais estão ordenadas alfabeticamente. As abreviações realizadas no texto referente às medidas são: indivíduos (ind.), comprimento (comp.), diâmetro oral (D.O.) e largura (larg.). As referências citadas logo abaixo dos nomes científicos referem-se primeiro àquela da descrição original e, em seguida, àquelas utilizadas para a identificação das espécies.

\section{Enquadramento taxonômico das espécies}

Filo Ciliophora Doflein, 1901

Classe Polihymenophorea Jankowski, 1967

Subclasse Spirotrichia Bütschli, 1889

Ordem Oligotrichida Bütschli, 1887

Subordem Tintinnina Kofoid \& Campbell, 1929

Codonellidae Kent, 1882

Codonaria Kofoid \& Campbell, 1939

Codonaria cistellula (Fol, 1884) Kofoid \& Campbell, 1929

Codonella Haeckel, 1873 emend. Kofoid \& Campbell, 1939

Codonella amphorella Biedermann, 1893

Codonella apicata Kofoid \& Campbell, 1929

Codonella aspera Kofoid \& Campbell, 1929

Codonella elongata Kofoid \& Campbell, 1929

Codonella galea Haeckel, 1873

Codonella olla Kofoid \& Campbell, 1929

Tintinnopsis Stein, 1867

Tintinnopsis campanula Daday, 1887

Tintinnopsis gracilis Kofoid \& Campbell, 1929

Tintinnopsis nana Lohmann, 1908

Tintinnopsis parvula Jörgensen, 1912

Tintinnopsis radix (Imhof, 1886) Brandt, 1906

Tintinnopsis tocantinensis Kofoid \& Campbell, 1929

Codonellopsidae Kofoid \& Campbell, 1929

Codonellopsis Jörgensen, 1899

Codonellopsis morchela (Cleve, 1900) Jörgensen, 1924

Codonellopsis orthoceras (Haeckel, 1873) Jörgensen, 1924

Codonellopsis ostenfeldi (Schmidt, 1901) Kofoid \& Campbell, 1929

Codonellopsis schabii (Brandt, 1906) Kofoid \& Campbell, 1929

Coxliellidae Kofoid \& Campbell, 1929

Climacocylis Jörgensen, 1924 emend. Kofoid \& Campbell, 1929

Clymacocylis scalaria (Brandt, 1906) Jörgensen, 1924

Clymacocylis scalaroides Kofoid \& Campbell, 1929

Clymacocylis sipho (Brandt, 1906) Kofoid \& Campbell,
1929

Coxliella Brandt, 1907

Coxliella fasciata (Kofoid, 1905) Brandt, 1906

Coxliella laciniosa (Brandt, 1906) Brandt, 1906

Cyttarocylidae Kofoid \& Campbell, 1929

Cyttarocylis Kofoid \& Campbell, 1929 emend. Kofoid \& Campbell 1939

Cyttarocylis brandti Kofoid \& Campbell, 1929

Cyttarocylis conica (Brandt, 1906) Kofoid \& Campbell, 1929

Epiplocylidae Kofoid \& Campbell, 1939

Epicancella Kofoid \& Campbell, 1939

Epicancella nervosa (Cleve, 1900) Kofoid \& Campbell, 1939

Epiplocylis Jörgensen, 1924 emend. Kofoid \& Campbell, 1939

Epiplocylis acuminata (Daday, 1887) Jörgensen, 1924

Epiplocylis blanda Kofoid \& Campbell, 1939

Epiplocylis undella (Ostenfeld \& Schmidt, 1901) Jörgensen, 1924

Petalotrichidae Kofoid \& Campbell, 1929

Acanthostomella Jörgensen, 1927

Acanthostomella minutissima Kofoid \& Campbell, 1929

Petalotricha Kent, 1882 emend. Brandt, 1907

Petalotricha ampulla (Fol, 1881) Kent, 1882

Ptychocylidae Kofoid \& Campbell, 1929

Favella Jörgensen, 1924

Favella ehrenbergii (Claparéde \& Laachmann, 1858) Jörgensen, 1924

Poroecus Cleve, 1902 emend. Kofoid \& Campbell, 1929

Poroecus curtus Kofoid \& Campbell, 1929

Tintinnididae Kofoid \& Campbell, 1929

Leprotintinnus Jörgensen, 1900

Leprotintinnus nordqvistii (Brandt, 1906) Kofoid \& Campbell, 1929

Undellidae Kofoid \& Campbell, 1929

Amplectella Kofoid \& Campbell, 1929

Amplectella monocollaria (Laackmann, 1910) Kofoid \& Campbell, 1929

Amplectella tricollaria (Laackmann, 1910) Balech, 1975

Undella Daday, 1887 emend. Kofoid \& Campbell, 1929

Undella claparedei (Entz, Sr., 1885) Daday, 1887

Undella globosa Brandt, 1906

Undella hyalina Daday, 1887

Undella lachmanni Daday, 1887

Undella perpusilla (Kofoid \& Campbell, 1929) Balech, 1975

Undella pistillum Kofoid \& Campbell, 1929

Undella subacuta Cleve, 1900

Undella subcaudata acuta (Jörgensen, 1924) Balech, 1975 


\section{RESULTADOS E DISCUSSÃO}

Nas nove famílias consideradas foram encontrados 43 táxons do grupo de espécie, distribuídos em 16 gêneros. Os gêneros melhor representados foram Undella, com 8 táxons infragenéricos, e Codonella com 6 táxons. As espécies com lóricas hialinas predominaram sobre as de lóricas aglutinantes. As quatro famílias restantes são tratadas em outro trabalho (Fernandes 2004). O tratamento sistemático das espécies determinadas é fornecido a seguir, por ordem alfabética de famílias.

\section{Codonellidae Kent, 1882 Codonaria cistellula (Fol, 1884) Figs 1, 1a, 59}

Cytarocylis cistellula Fol, 1884: 42, 556, 57, pl. 5, fig. 8.

Codonaria cistellula; Kofoid \& Campbell, 1939: 55-61, pl. 2, figs $6,13,16$, pl. 3 , figs 7,12 .- Balech, 1962: 57, pl. 2, figs 19-30, pl. 3, fig. 31 .

Descrição: lórica hialina amarelada a pardo escuro semelhante à ânfora, dividida em três porções; crista oral [termo cunhado por BALECH (1962), que a denomina também de precolar], colar e cesto, as duas últimas limitadas por uma constrição conspícua. A crista oral é um cone truncado com o lado maior apoiado no colar; sua superfície apresenta alvéolos circulares unidos ou separados; extremidade denticulada, raramente lisa. $\mathrm{O}$ colar é um cone truncado invertido recoberto por alvéolos. $\mathrm{O}$ cesto é ovóide a esférico, alveolado e provido de janelas circulares grandes, espalhadas pela superfície em arranjos variáveis. Extremidade aboral obtusa ou discretamente rostrada. Os alvéolos são pentagonais ou hexagonais, de lados espessados.

Medidas (4 ind.): comp. 81-82 $\mu \mathrm{m}$; larg. $65 \mu \mathrm{m}$; D.O. 32$34 \mu \mathrm{m}$; altura do colar $23-25 \mu \mathrm{m}$ : altura da plataforma $8 \mu \mathrm{m}$; constrição $42-43 \mu \mathrm{m}$.

Comentários: lórica bastante variável quanto a sua morfologia geral e número e disposição das janelas. BALECH (1962) mostrou o polimorfismo acentuado desta espécie, sinonimizando algumas espécies próximas, descritas em KoFoID \& Campbell $(1929,1939)$ : C. mucronata Kofoid \& Campbell, C. oceanica (Brandt), C. benguelensis (Kofoid \& Campbell), C. australis (Kofoid \& Campbell) e C. lata Kofoid \& Campbell.

Ocorrência nas amostras: Operação Monitor IV (estação 13/100 m); Operação Sueste IV (estações 6600-6604); Projeto COROAS (estações 1, 3, 9/150-100 m, 17/130-100 m).

\section{Codonella amphorella Biedermann, 1893 Figs 2-3, 60}

Codonella amphorella Biedermann, 1893: 16-17, pl. 2, fig. 1.Balech, 1962: 55, pl. 1, fig. 11.- Marshall, 1969: 2/3, pl. 3, fig. 2.- Balech \& Souto, 1980: 5, fig. 4.

Descrição: lórica aglutinante, dividida em três porções: colar, cesto e cauda. O colar apresenta-se como um cone truncado de lados convexos, podendo dilatar-se próximo à extre- midade oral; sua superfície apresenta enrugamentos discretos e detritos. Uma constrição limita o início do cesto ovóide a esférico, o qual termina em cauda afilada, mais ou menos cônica e de extremidade obtusa. Parede relativamente delgada, provida de alvéolos distribuídos irregularmente e intercalados por janelas; mais numerosos próximo à região mediana da lórica. Detritos retangulares ou triangulares agregados no cesto, raramente no colar. Cesto constituído de alvéolos menores, semelhantes a uma hemisfera com uma abertura circular no centro; janelas de tamanho variável, elípticas ou circulares. Um diafragma constituído por 14-16 peças triangulares justapostas veda a abertura do cesto, na região anterior.

Medidas (2 ind.): comp. $88 \mu \mathrm{m}$; larg. $45 \mu \mathrm{m}$; D.O. $41 \mu \mathrm{m}$; altura do colar $22 \mu \mathrm{m}$ : altura do cesto $49 \mu \mathrm{m}$; comprimento da cauda $17 \mu \mathrm{m}$; diafragma com 14-16 peças; 18 -22 micronúcleos. Comentários: C. rapa Kofoid \& Campbell foi considerada por BALECH \& Souto (1980) sinonímia de C. amphorela.

Ocorrência nas amostras: Operação Monitor IV (estações 9/100 m, 13/100 m); Operação Sueste IV (estações 6604, 6612, 6614); Projeto COROAS (estações 1, 7, 9, 19/150-100 m).

\section{Codonella apicata Kofoid \& Campbell, 1929 Figs 61-65}

Codonella apicata Kofoid \& Campbell, 1929: 53, fig. 116.- Balech, 1962: 53, pl. 1, figs 13-16; Marshall, 1969: 2/3, pl. 3, fig. 3.

Descrição: lórica hialina semelhante à ânfora alargada, composta por cesto e colar. Colar de lados fortemente convexos, às vezes formando uma pequena plataforma em sua extremidade. Parede reticulada podendo apresentar alguns alvéolos maiores. Constrição evidente, formando uma linha refringente. Cesto globoso, de extremidade aboral acuminada. Parede composta por alvéolos de diferentes tamanhos, e alvéolos maiores poligonais.

Medidas (8 ind.): Comp. 63,2-65,8 $\mu \mathrm{m}$; D.O. 42-42,5 $\mu \mathrm{m}$.

Comentários: Diafragma presente. Espécie semelhante à

C. perforata, diferindo desta por apresentar extremidade aboral acuminada e colar mais convexo (BALECH 1962, MARSHALl 1969). As dimensões são semelhantes às encontradas por BALECH (1962). Ocorrência nas amostras: Operação Sueste IV (estações 6599, 6601, 6603, 6604, 6614, 6618); Projeto COROAS (estações $1,3,7,9,13 / 150-100$ m, 17/130-100 m).

\section{Codonella aspera Kofoid \& Campbell, 1929 Fig. 4, 4a}

Codonella aspera Kofoid \& Campbell, 1929: 55, fig. 101.- Balech, 1959: 18, pl. 2, figs 21-28, pl. 22, fig. 330.- Balech \& Souto, 1980: 5, fig. 3.

Descrição: lórica em forma de ânfora, dividida em duas porções por uma constrição evidente. A porção anterior (colar) inclui a região oral e apresenta-se semicônica a quase retangular, de lados paralelos, composto de retículos hexagonais conspícuos. A porção posterior forma um cesto ovóide de extremidade aboral acuminada. As paredes da lórica no cesto 

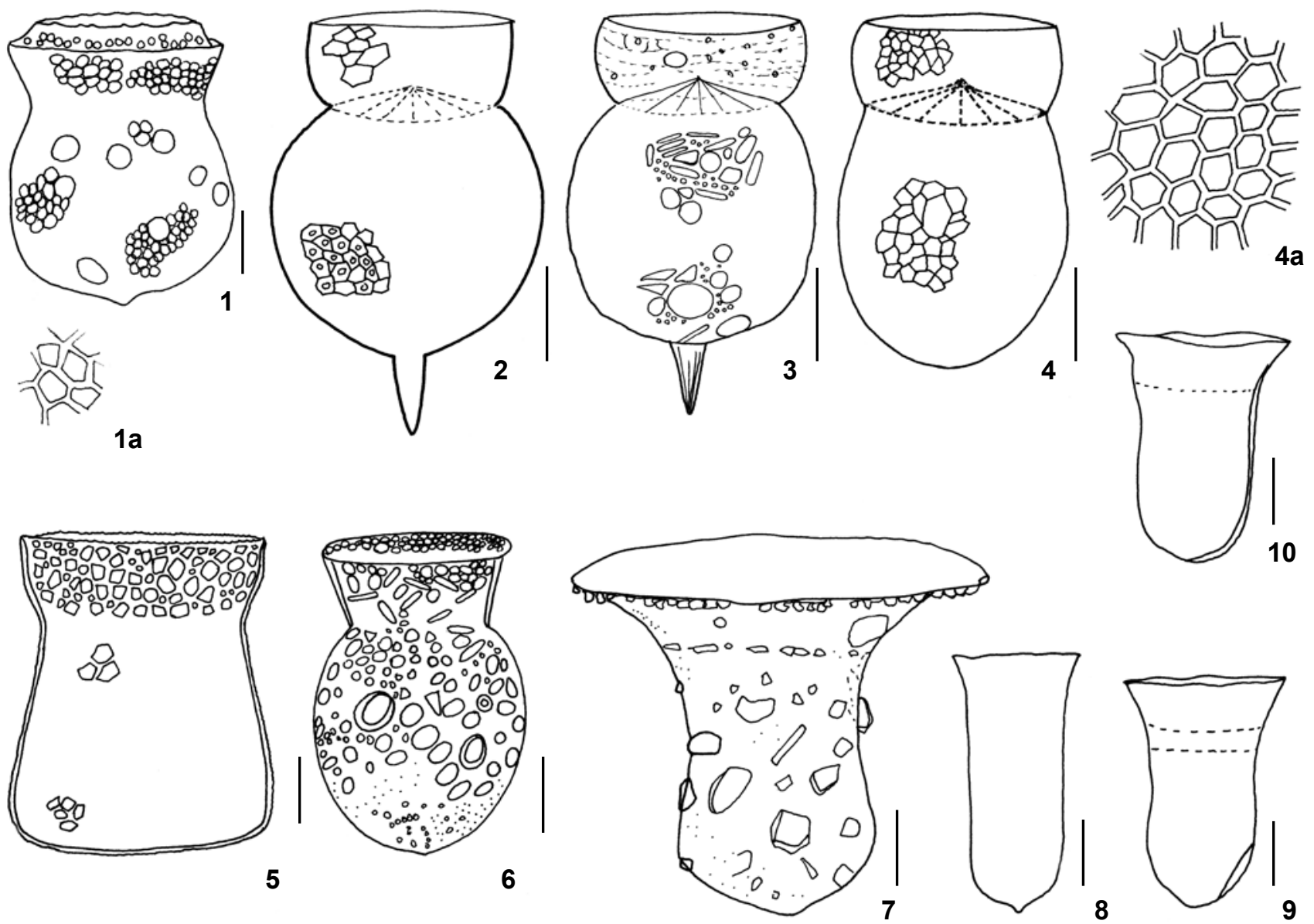

5

6
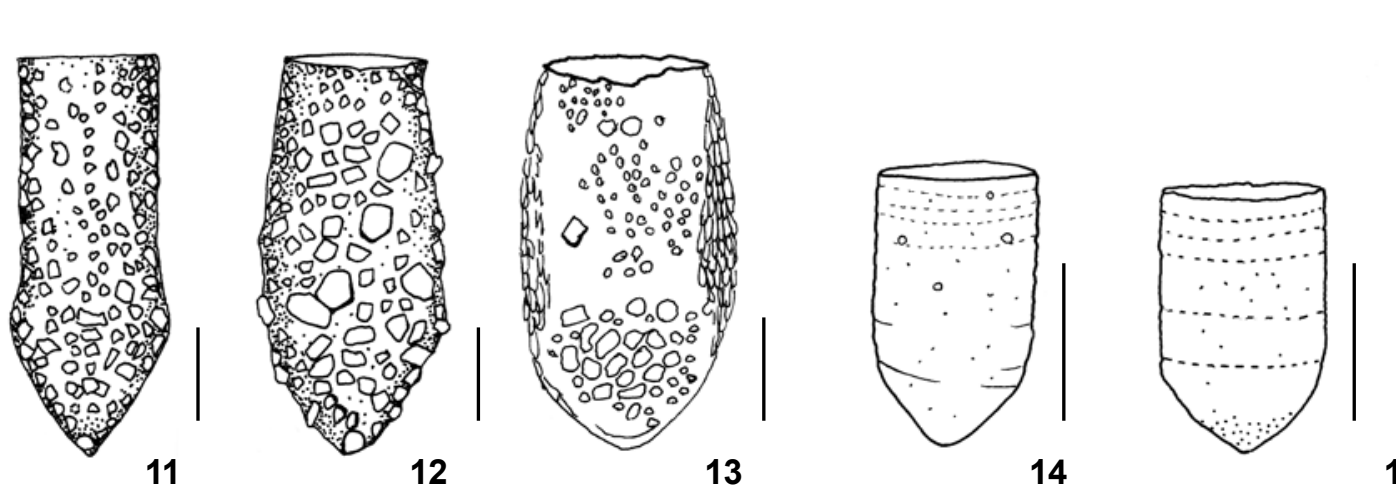

14

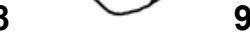

Figuras 1-16. (1, 1a) Codonaria cistellula, na figura 1a detalhe dos alvéolos poligonais; (2-3) Codonella amphorella; (4, 4a) Codonella aspera, com detalhe dos alvéolos poligonais na figura 4a; (5) Codonella olla; (6) Codonella galea; $(7,10)$ Tintinnopsis campanula; $(11,13)$ Tintinnopsis gracilis; (14-15) Tintinnopsis nana; (16) Tintinnopsis parvula. Barras de escala $=20 \mu \mathrm{m}$.

apresentam um reticulado provido de alvéolos hexagonais hemisféricos com um orifício central, geralmente cobertas de partículas (especialmente cocólitos); às vezes livre de detritos. Diafragma composto por 8-10 peças. Em algumas lóricas os alvéolos apresentam tamanho aproximadamente igual, exceto na parte central do cesto, onde são maiores.

Medidas (3 ind.): comp. 99-105 $\mu \mathrm{m}$; larg. 62-64 $\mu \mathrm{m}$; D.O. $48-48,5 \mu \mathrm{m}$.

Revista Brasileira de Zoologia 21 (3): 551-576, setembro 2004 


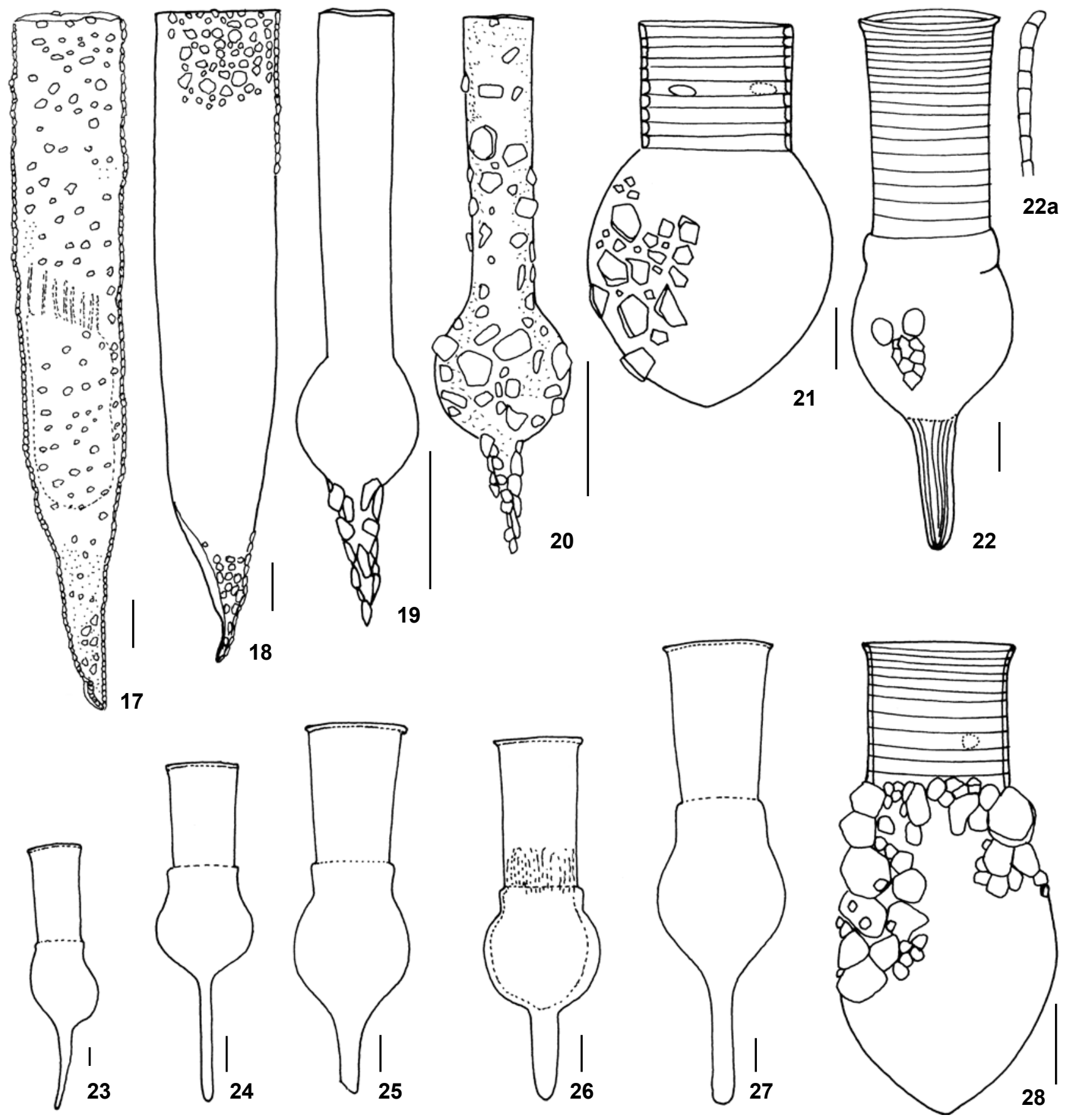

Figuras 17-28. $(17,18)$ Tintinnopsis radix; $(19,20)$ Tintinnopsis tocantinensis; $(21)$ Codonellopsis morchella; $(22,27)$ Codonellopsis orthoceras, mostrando variações morfológicas da lorica; (28) Codonellopsis schabii. Barras de escala $=20 \mu \mathrm{m}$.

Comentários: BaLECH \& Souto (1980) descreveram um mecanismo de fechamento na constrição formado por 10-12 "lâminas", semelhantes ao observado em nosso material, que

Revista Brasileira de Zoologia 21 (3): 551-576, setembro 2004 denominamos "diafragma". Para sinonímias, consulte BALECH (1959). Algumas lóricas são muito semelhantes à C. amphorella, especialmente quando livres de detritos. 


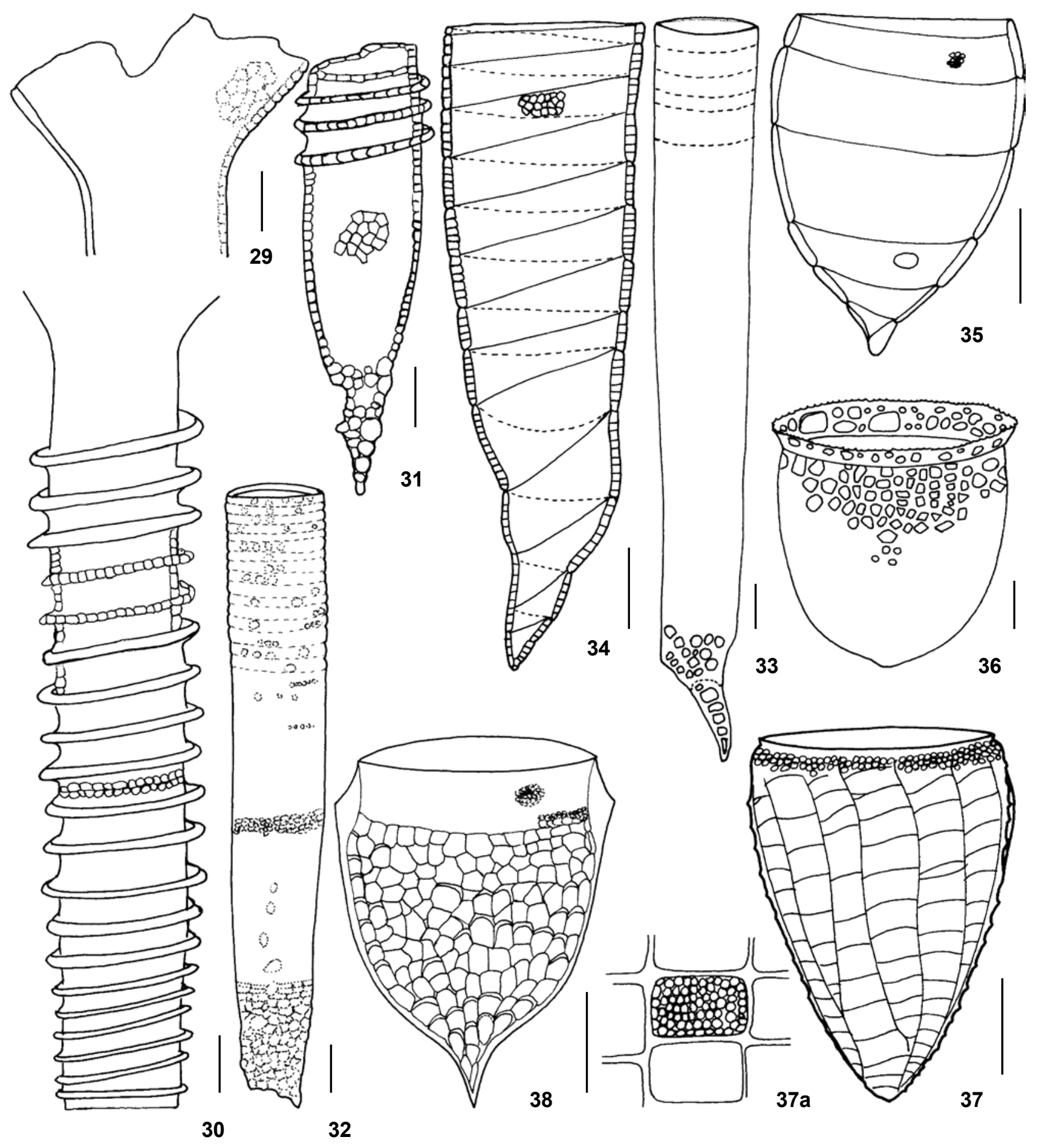

Figuras 29-38. (29, 30) Climacocylis scalaria, na figura 29 detalhe da região aboral; (31) Climacocylis scalaroides; (32, 33) Climacocylis sipho, note o apêndice caudal alveolado na figura 33; (34) Coxliella fasciata; (35) Coxliella laciniosa; (36) Cytarocylis brandti; (37, 37a) Epicancella nervosa, na figura 37a detalhe da parede mostrando costelas quadrangulares e pontuações; (38) Epiplocylis acuminata. Barras de escala $=20 \mu \mathrm{m}$. 
Ocorrência nas amostras: Operação Monitor IV (estações 22, 22/10 m); Operação Sueste IV (estações 6599, 6601, 6603, 6604, 6610-6614); Projeto COROAS (estações 7, 9, 13/150$100 \mathrm{~m}, 17 / 130-100 \mathrm{~m}, 19 / 130-79 \mathrm{~m}$ ).

\section{Codonella elongata Kofoid \& Campbell, 1929 Figs 66-69}

Codonella elongata Kofoid \& Campbell, 1929: 59, fig. 102.Brandt, 1906, pl. 4, figs 20-21, pl. 10, fig. 9.- Brandt, 1907: 12.- Balech, 1959: 18, pl. 2, figs 21-28, pl. 22, fig. 330 (para discussão e comparação).- Marshall, 1969: 2/3, pl. 3, fig. 5.

Descrição: lórica hialina em forma de ânfora, composta por colar e cesto, separados por uma constrição evidente. Colar cônico-truncado de borda lisa com um pequeno espessamento hialino; parede reticulada com alvéolos quadrangulares e poligonais irregulares. Cesto ovóide, ligeiramente acuminado na região aboral; parede composta por alvéolos justapostos grandes elipsóides a quase quadrangulares, dispostos irregularmente na superfície. Próximo a extremidade aboral os alvéolos apresentam tamanho muito reduzido. Diafragma presente, visível na região central do cesto na figura 66 .

Medidas (4 ind.): comp. 94,8-95,6 $\mu \mathrm{m}$, D.O. $54 \mu \mathrm{m}$.

Comentários: espécie semelhante a $C$ galea Haeckel, da qual difere por apresentar cesto mais alongado, extremidade aboral mais aguda e alvéolos regulares e justapostos. Em $C$. galea os alvéolos do cesto são mais irregulares (tamanho e forma), ocorrendo ainda janelas. Espécie criada por Koford \& CAmpbell (1929) com base nas ilustrações de Brandt (1907). BALECH (1959) considerou C. elongata sinonímia de C. aspera mas, no presente trabalho, foi possível verificar diferenças razoáveis entre as duas. Nossos exemplares são semelhantes ao ilustrado em Brandt (1907) e MarShall (1969). Balech analisou centenas de lóricas e deve ter observado transição entre as espécies, embora uma forma com alvéolos semelhantes aos encontrados em nosso material não tenha sido ilustrada. Portanto, preferimos manter C. elongata como válida, mas apenas a partir do material de BRANDT (1907).

Ocorrência nas amostras: Operação Sueste IV (estações 6599, 6602-6604, 6615); Projeto COROAS (estações 1, 9/150$100 \mathrm{~m})$.

\section{Codonella galea Haeckel, 1873} Figs 6, 70-71

Codonella galea Haeckel, 1873: 51, 52, 53, pl. 28, figs 8-9.- Brandt, 1906 pl. 5, figs 9-10; pl. 6, figs 1-2; pl. 10, fig. 10.- Balech, 1959: 19, pl. 2, figs 29-33; pl. 3, figs 34-35.

Descrição: lórica hialina semelhante à ânfora, dividida em duas porções (colar e cesto) por uma constrição evidente. Colar de lados convexos e superfície provida de alvéolos poligonais irregulares, de diferentes tamanhos. Extremidade oral crenulada. Cesto globóide a esférico, extremidade aboral acuminada. Superfície provida de alvéolos pequenos a grandes, particularmente na região mediana da lórica. Diafragma presente, 12-14 lâminas triangulares.

Medidas (4 ind.): comp. 93-108 $\mu \mathrm{m}$, larg. na região aboral 74-81 $\mu \mathrm{m}$; D.O. $64 \mu \mathrm{m}$; constrição $62 \mu \mathrm{m}$; altura do colar $22 \mu \mathrm{m}$. Comentários: espécie morfologicamente muito semelhante à ilustrada por BALECH (1959), diferindo apenas pela extremidade aboral acuminada. O autor denominou janelas às aberturas maiores, mas preferimos considerá-las alvéolos devido à sua semelhança com os demais alvéolos da parede. C. galea difere de C. aspera por apresentar colar de lados retos e convergentes, borda oral crenulada e lórica hialina. Comentários: O exemplar da Fig. 6 foi provisoriamente alocado como C. galea Haeckel, encontrada em BALECH (1959) e BRANDT (1907), e cujas medidas são: comp. 71-73 $\mu \mathrm{m}$, larg. na região aboral $47 \mu \mathrm{m}$; D.O. $46 \mu \mathrm{m}$; constrição $35 \mu \mathrm{m}$; altura do colar $14 \mu \mathrm{m}$. Entretanto, há muitas diferenças em relação à C. galea como borda oral lisa e espessada, colar de lados retos e dimensões sempre menores do que C. galea (comp.

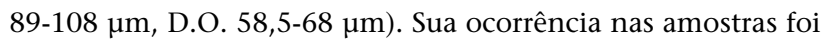
na Operação Sueste IV (estação 6604).

Ocorrência nas amostras: Operação Sueste IV (estações 6599, 6602-6604, 6612); Projeto COROAS (estações 9/150$100 \mathrm{~m})$.

\section{Codonella olla Kofoid \& Campbell, 1929 Figs 5,72}

Codonella olla Kofoid \& Campbell, 1929: 63-64, fig. 115.- Brandt, 1906, pl. 9, fig. 1.- Brandt, 1907: 13.-Campbell, 1942: 11, figs 15-16.- Balech, 1962: 56, pl. 2, figs 17-18.

Descrição: lórica hialina de cor marrom escuro, quase negro e paredes espessadas, dividida em duas porções: colar e cesto, separados por uma constrição conspícua. Colar cônicotruncado de lados quase paralelos e convexos; extremidade oral um pouco dilatada e denticulada; dentículos pequenos. Cesto semelhante a um trapézio isóscele de lados ligeiramente convexos, os quais formam uma curva na região aboral. Extremidade aboral quase reta. Superfície da lórica provida de prismas poligonais separados por pequenas traves de paredes lisas em alto-relevo, ou seja, num plano superior aos prismas, formando pequenos enrugamentos quando se observa as laterais da lórica. Protozoário ocupando todo o volume do cesto, membranelas na região do colar.

Medidas ( 2 ind.): comp. $88 \mu \mathrm{m}$, larg. na região aboral $70 \mu \mathrm{m}$; D.O. $74 \mu \mathrm{m}$; constrição $59 \mu \mathrm{m}$; altura do colar $23 \mu \mathrm{m}$.

Comentários: espécie pouco conhecida e mal delimitada por Kofoid \& CAMpbell (1929), a partir de Codonella nationalis forma "e" de BRANDT (1907), posteriormente encontrada por Campbell (1942) com morfologia muito diferente dos trabalhos anteriores. O exemplar de BALECH (1962) sob C. aff. ola é bastante semelhante ao do presente trabalho.

Ocorrência nas amostras: Operação Sueste IV (estação 6604); Projeto COROAS (estações 7, 9/150-100 m). 

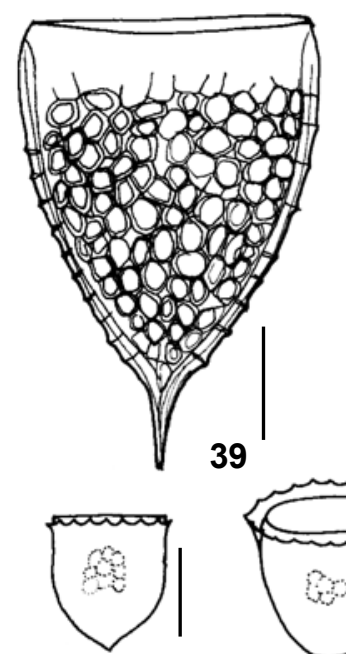

42

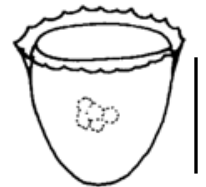

43
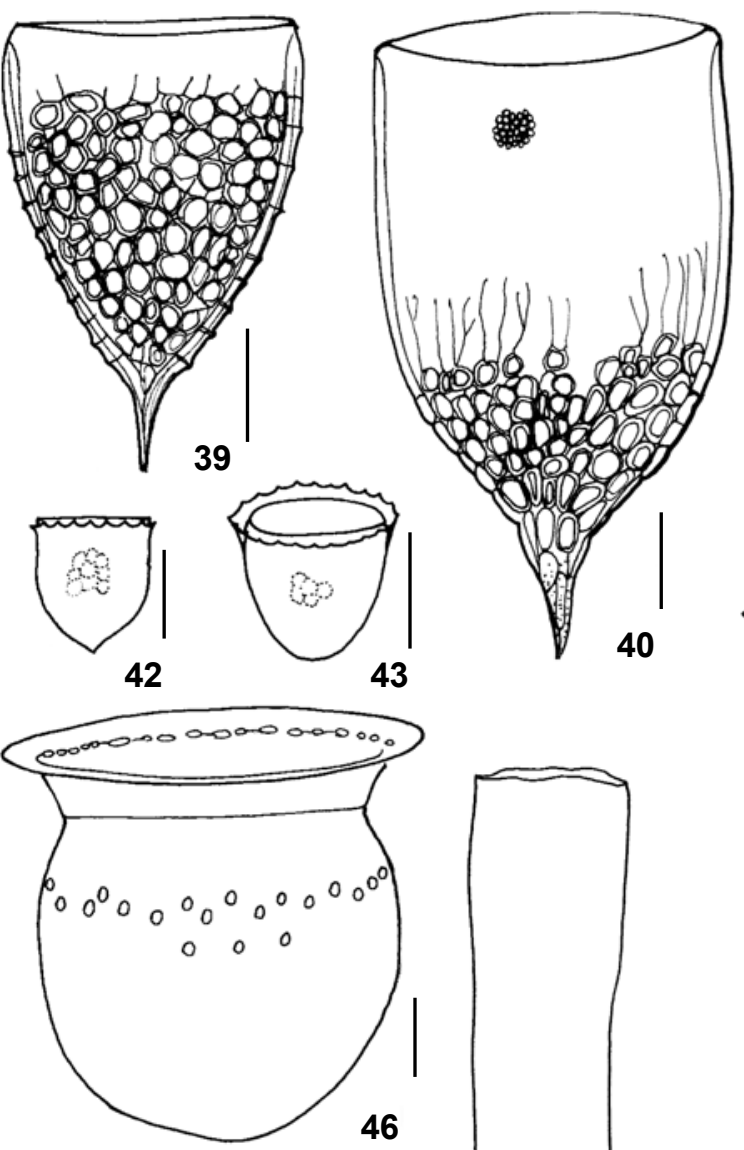

46

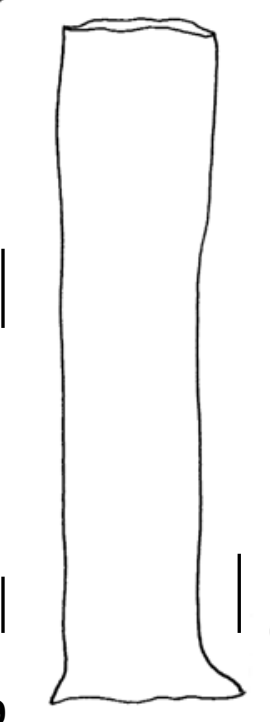

48

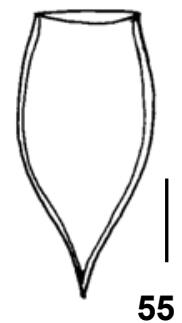

49

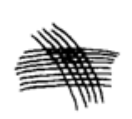

$55 a$

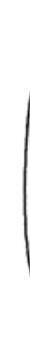

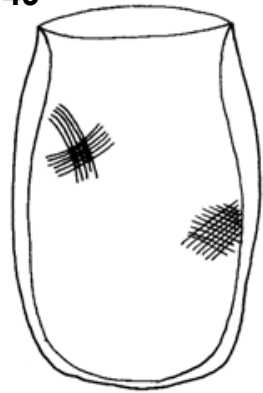

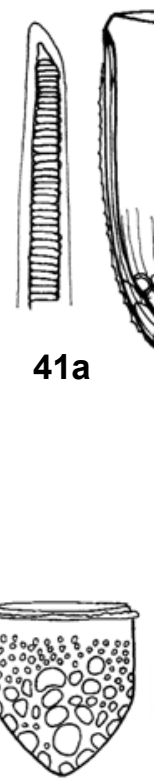

44
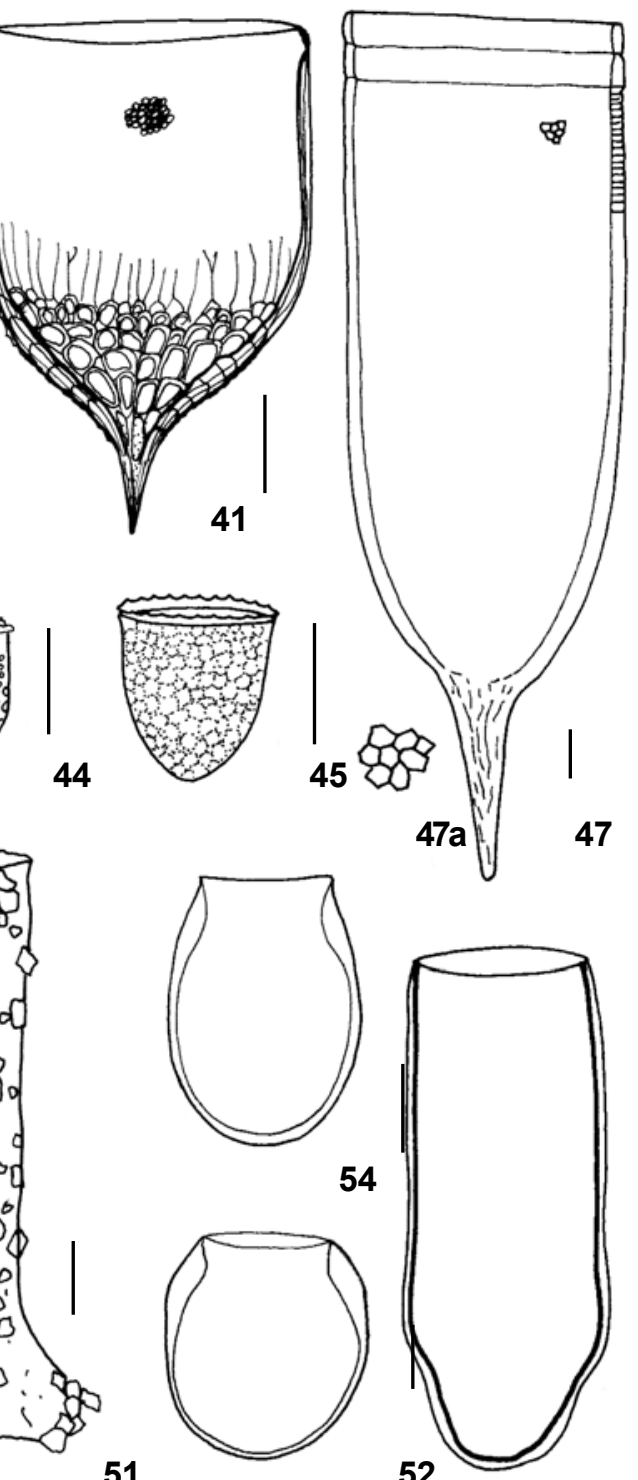

53
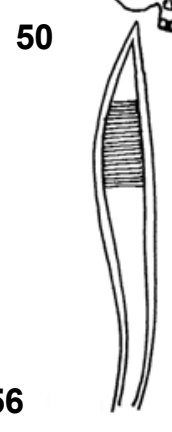

51

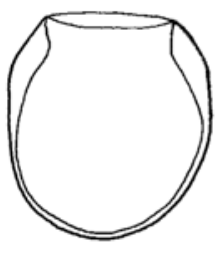

52
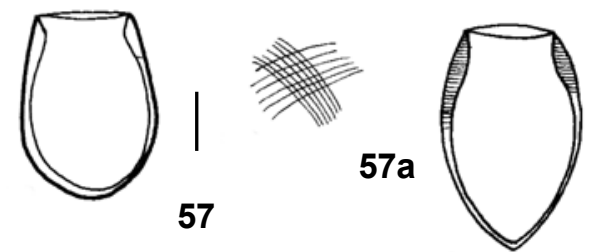

58

Figuras 39-58. (39) Epiplocylis blanda; (40-41) Epiplocylis undella, mostrando detalhe da parede na figura 41a; (42-45) Achantostomella minutissima; (46) Petalotricha ampula; (47) Favella ehrenbergii, mostrando detalhe dos alvéolos da parede na figura 47a; (48-49) Poroecus curtus; (50, 51) Leprotintinnus nordqvstii; (52) Undella globosa; (53) Undella hyalina; (54) Undella perpusilla. (55) Undella lachmanni e detalhe das estrias da parede na figura 55a; (56) Undella pistilum, mostrando detalhe da estrutura da parede na figura 56a; (57) Undella subacuta; (58) Undella subcaudata subacuta e detalhe das estrias da parede na figura 58a. Barras de escala $=20 \mu \mathrm{m}$. 


\section{Tintinnopsis campanula Daday, 1887 Figs 7-10}

Tintinnopsis campanula Daday, 1887: 551, pl. 19, figs 16, 18.Balech, 1948: 10-11, pl. 3, figs 25, 26, pl. 4, figs 27-33, pl. 4, figs 36-39.- Bakker \& Phaff, 1976: 105, figs 9a-g.

Descrição: lórica aglutinante com partículas delicadas e grosseiras aderidas por toda a sua superfície. Região oral expandida em forma de disco com a borda irregular. Abaixo do disco os lados são convergentes e côncavos até formar uma constrição, ou tornam-se retos na região mediana. Região aboral de lados convexos, extremidade aboral larga e arredondada. Várias lóricas apresentaram desde um disco oral apenas incipiente até totalmente desenvolvido.

Medidas (13 ind.): comp. 80-86 $\mu \mathrm{m}$; larg. 40-42 $\mu \mathrm{m}$; D.O. 75-84 $\mu \mathrm{m}$.

Comentários: No presente trabalho foram encontradas várias formas intermediárias entre T. buetschlii e T. buetschlii var. mortensenii sensu BALECH (1948), esta última elevada à nível específico por KoFoId \& CAMpBell (1929). Entretanto, seguimos o procedimento adotado por BaKker \& Phaff (1976) que discutiu os problemas taxonômicos da espécie e considerou-as como sinônimas de T. campanula (Ehrenberg) Daday. BALECH (1959) trata separadamente $T$. campanula e $T$. buetschlii, baseado na presença de "apêndice aboral" na primeira, inexistente na segunda. Entretanto, o autor comenta que encontrou formas atrofiadas (sem apêndice) e transicionais para T. buetschlii. LavaLPeuto \& Browlee (1986) mostraram que os taxa citados representam diferentes fases do ciclo vital de T. campanula.

Ocorrência nas amostras: Operação Sueste IV (estação 6597,6608); PROANTAR XI (estações 19-25).

\section{Tintinnopsis gracilis Kofoid \& Campbell, 1929 Figs 11-13}

Tintinnopsis gracilis Kofoid \& Campbell, 1929: 36, fig. 37.Balech, 1948: 7, pl. 2, figs 17-18.- Souto, 1970a: 193, figs 13-19.

Descrição: lórica aglutinante aproximadamente cilíndrica, recoberta por partículas de areia com tamanho semelhante, de lados paralelos desde a borda oral até o terço posterior, quando se inicia uma pequena dilatação de lados convexos a retos, formando um cone de extremidade aboral aguda.

Medidas (18 ind.): comp. 95-102 $\mu \mathrm{m}$; larg. 32-34 $\mu \mathrm{m}$; D.O. 29-30 $\mu \mathrm{m}$.

Comentários: veja em T. parvula.

Ocorrência nas amostras: PROANTAR XI (estações 19-25).

\section{Tintinnopsis nana Lohmann, 1908}

Figs 14-15

Tintinnopsis nana Lohmann, 1908: 292-294, pl. 17, fig. 12.Hada, 1938: 94, fig. 5a-c.- Balech, 1959: 13, pl. 1, fig. 1.

Descrição: lórica cilíndrica em forma de projétil, agluti- nante de partículas arenosas finas; região aboral cônica com extremidade obtusa, ás vezes acuminada. Estriações transversais discretas ocorrem na lórica, particularmente próximo à região oral. Algumas partículas dispostas em fileiras longitudinais.

Medidas (20 ind.): comp. 33-35 $\mu \mathrm{m}$, D.O. 19-20 $\mu \mathrm{m}$.

Comentários: D.O. com medidas maiores do que as encontradas por HADA (1938) (d.o 16-18 $\mu \mathrm{m}$, comp. 30-35 $\mu \mathrm{m}$ ) e Balech (1959) (d.o 16-17,5 $\mu \mathrm{m}$, comp. 44-47 $\mu \mathrm{m}$ ). A espécie também se assemelha à certos morfótipos de T. beroidea Stein, mas com dimensões inferiores. T. beroidea é bastante polimórfica, como mostrado por BAKKer \& PHAFF (1976).

Ocorrência nas amostras: Operação Sueste IV (estação 6608); PROANTAR XI (estações 1, 2, 15-23).

\section{Tintinnopsis parvula Jörgensen, 1912 Fig. 16}

Tintinnopsis parvula Jörgensen, 1912: 2-3.- Kofoid \& Campbell, 1929: 43, fig. 28.- Balech, 1948: 7, pl. 3, figs 19-21.- Souto, 1970a: 191, figs 7-12.

Descrição: lórica aglutinante densamente recoberta por partículas de tamanho variável; lados divergentes a paralelos até o terço posterior, o qual pode formar um cesto cônico-convexo á subesférico (pouco comum), de extremidade aboral obtusa. A parede da lórica freqüentemente é irregular e de morfologia variável.

Medidas (23 ind.): comp. 78-89 $\mu \mathrm{m}$; larg. 39-41 $\mu \mathrm{m} ;$ D.O. 28-29 $\mu \mathrm{m}$; comp. do cesto 40-43 $\mu \mathrm{m}$; comp. do cone 45-46 $\mu \mathrm{m}$.

Comentários: Em T. gracilis a extremidade é aguda, e os lados são paralelos na maior parte dos indivíduos encontrados.

Ocorrência nas amostras: PROANTAR XI (estações 19, 2125).

\section{Tintinnopsis radix (Imhof, 1886) Figs $17-18,73$}

Codonella radix Imhof, 1886: 103.

Tintinnopsis radix; Brandt, 1906: 12; Balech, 1959: 17, pl. 2, figs 19-20.- Souto, 1970a: 191, fig. 5.

Descrição: lórica cilíndrica em sua maior extensão (aproximadamente 2/3), aglutinando grãos de areia. Lados paralelos, tornando-se convergentes na parte posterior. Região oral lisa, extremidade algo irregular. Região aboral provida de um apêndice caudal cônico afilado e aberto lateralmente. Alguns indivíduos apresentam poucas partículas aderidas; voltas espirais pouco conspícuas na região oral; raramente a volta mais próxima da extremidade oral é bem evidente. Protozoário ocupando 40$50 \%$ do volume da lórica. Algumas lóricas aglutinam poucas partículas de areia e apresentam voltas espirais bem evidentes. Medidas (34 ind.): comp. 269-410 $\mu \mathrm{m}$; larg. 43-46 $\mu \mathrm{m}$; D.O. 43-46 $\mu \mathrm{m}$.

Ocorrência nas amostras: PROANTAR XI (estações 16, 1825). 


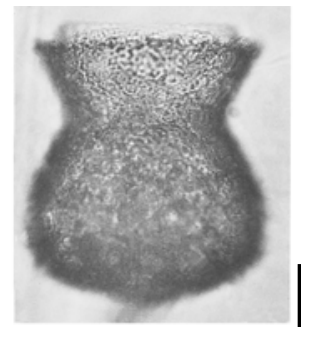

59
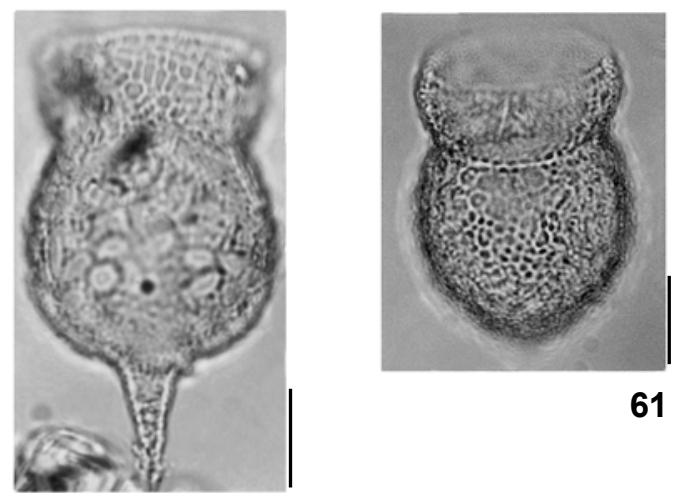

61

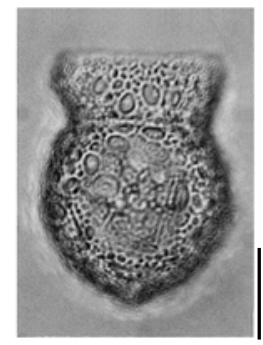

62
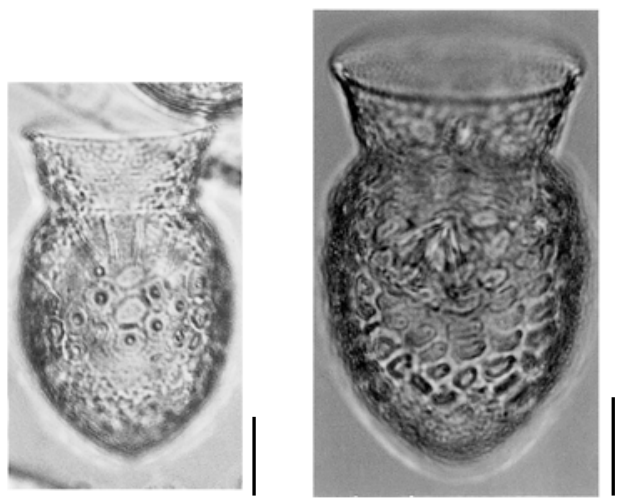

66

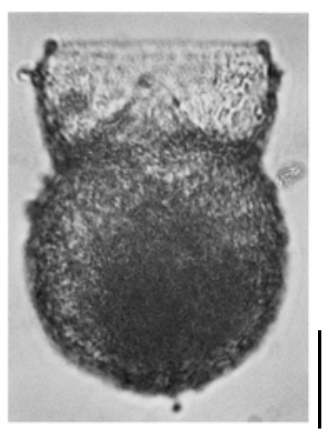

65
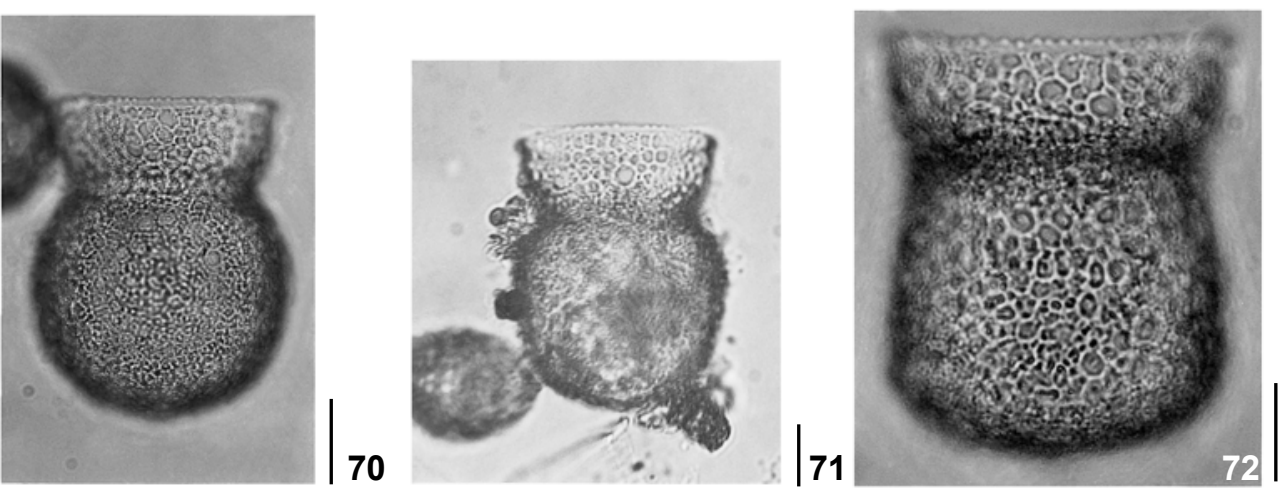

Figuras 59-72. (59) Codonaria cistellula; $(60)$ Codonella amphorella; $(61,65)$ Codonella apicata; $(66,69)$ Codonella elongata; $(70,71)$ Codonella galea; (72) Codonella ola. Barras de escala $=20 \mu \mathrm{m}$.

\section{Tintinnopsis tocantinensis Kofoid \& Campbell, 1929 Figs 19-20}

Tintinnopsis aperta var. a Brandt, 1906, pl. 25, figs 2, 7.- Brandt, 1907: 19.

Tintinnopsis tocantinensis Kofoid \& Campbell, 1929: 48, fig. 46. Tintinnopsis tocantinensis; Balech, 1948: 6, pl. 2, figs 13-16.Sousa \& Silva, 1952: 613, pl. 1, fig. 116.

Descrição: lórica aglutinante densamente revestida por partículas arenosas. Região anterior cilíndrica ou discretamen- te cônico-truncada, devido à convergência dos lados, seguindo-se um curto cesto esférico provido de apêndice caudal robusto cônico e extremidade aguda. Borda oral lisa e reta. A região anterior pode ser desde pouco desenvolvida até bastante evidente, de tamanho superior ao cesto e apêndice caudal somados.

Medidas (8 ind.): comp. 108-171 $\mu \mathrm{m}$; larg. 28-35 $\mu \mathrm{m}$; D.O. 19-21 $\mu \mathrm{m}$.

Ocorrência nas amostras: Operação Sueste IV (estação 6597, 6607, 6608); PROANTAR XI (estações 16, 19, 20).

Revista Brasileira de Zoologia 21 (3): 551-576, setembro 2004 


\section{Codonellopsidae Kofoid \& Campbell, 1929 Codonellopsis morchela (Cleve, 1900)}

Fig. 21

Codonella morchela Cleve, 1900: 969, fig. 2.

Codonellopsis morchela; Jörgensen, 1924: 99, 100.- Balech, 1971: 169, pl. 37, fig. 716.

Descrição: lórica aglutinante, dividida em duas porções: colar e corpo (ou cesto). Colar hialino bilaminar, extremidade oral discretamente dilatada; paredes paralelas entre si, apresentando altura semelhante a do cesto e formado por 10-12 voltas espirais. Duas fenestras elípticas a circulares situam-se na quinta volta (contando-se a partir da base). O cesto é ovóide, agregando diferentes partículas relativamente grosseiras; não há "ombros". Extremidade aboral obtusa a acuminada. Parede com estrutura primária delicada.

Medidas (8 ind.): comp. 108-115 $\mu \mathrm{m}$; larg. 54-55 $\mu \mathrm{m}$; D.O. $33 \mu \mathrm{m}$; cesto formado por 10-12 voltas espirais.

Comentários: um grande número de espécies muito próximas foi descrito por Kofoid \& CAmpbell (1929), dificultando identificação confiável. Para discussão sobre sinonímias, veja Hada (1938), Balech (1959) e Alder (1999). Este último autor considerou C. schabii como uma forma de C. morchella, procedimento não seguido no presente trabalho, no qual foram separadas três espécies, diferenciadas a seguir: 1) C. morchela, colar com 9-11 voltas espirais e fenestras, ausência de ombros e apêndice caudal, cesto esférico; 2) C. orthoceras, lórica grande, colar com 14-26 voltas espirais sem fenestras, ausência de ombros, apêndice caudal evidente; 3) C. schabii, colar com voltas espirais e fenestras, presença de ombros, cesto elipsóide. Ocorrência nas amostras: Operação Sueste IV (estações 6596-6598, 6608, 6609, 6620); PROANTAR XI (estação 8).

\section{Codonellopsis orthoceras (Haeckel, 1873)}

\section{Figs $22-27,74$}

Codonella orthoceras Haeckel, 1873: 567, pl.28, fig.10.

Codonellopsis orthoceras; Jörgensen, 1924: 5, 98-100, 106.Balech, 1959: 23, pl. 5, figs 79-80; pl. 6, figs 85-90.- Balech, 1962: 100, pls 4-6, fig. 55.

Descrição: lórica aglutinante, dividida em três regiões: colar, cesto (ou corpo) e cauda. Colar hialino pardo-amarelado de lados discretamente convergentes a paralelos, composto por voltas espirais. Sua parede é composta por duas lâminas que envolvem uma camada de pequenos alvéolos, conferindo uma aparência granular ao colar. Não há fenestras. Extremidade oral voltada para o exterior, com diâmetro pouco superior ao das voltas espirais. Corpo aglutinante (às vezes quase hialino) provido de uma região anterior de lados paralelos e seguida por dilatação que o torna globoso ou esférico. Da extremidade posterior do corpo surge uma cauda robusta, cônica e de ápice obtuso. Em alguns exemplares o comprimento da cauda era quase o mesmo daquele do corpo. Parede do cesto provida de alvéolos poligonais e outras ornamentações pouco conspícuas, e 2-4 janelas circulares evidentes (Fig. 74).

Medidas (15 ind.): comp. 220-270 $\mu \mathrm{m}$; larg. 78-82 $\mu \mathrm{m}$; D.O. $60-64 \mu \mathrm{m}$; $14-26$ voltas espirais. Uma lórica encontrada com 32 voltas espirais.

Comentários: espécie bastante típica devido às suas dimensões e apêndice caudal. Veja também discussão em C. morchela.

Ocorrência nas amostras: Operação Monitor IV (estações 17-19, 19/10 m, 24/100 m, 26/100 m); Operação Sueste IV (estações 6599, 6602-6604, 6612-6616); Projeto COROAS (estações $1,3,5,7,9,17 / 130-100 \mathrm{~m})$.

\section{Codonellopsis ostenfeldi (Schmidt, 1901)}

Fig. 75

Codonella ostenfeldi Schmidt, 1901: 187, fig. 4.- Brandt, 1906, pl. 14, figs 1, 2, pl. 15, fig. 2.- Brandt, 1907: 123.

Codonellopsis ostenfeldi; Kofoid \& Campbell, 1929: 84, fig. 160.

Descrição: lórica aglutinante, partículas grosseiras, e formada por duas regiões: colar e corpo. Colar hialino composto por voltas espirais iguais e de lados paralelos; extremidade oral voltada para o exterior. Várias fenestras ocorrem nas voltas, aproximadamente 8-12 por volta, arredondadas nos indivíduos menores e alongadas nos maiores. As voltas espirais próximo à abertura oral são mais estreitas e não apresentam fenestras. Corpo ovoíde, extremidade anterior reta. Extremidade posterior arredondada ou ligeiramente acuminada.

Medidas (9 ind.): comp. 125-159 $\mu \mathrm{m}$; larg. 63-65 $\mu \mathrm{m}$; diâmentro oral 38-39 $\mu \mathrm{m}$; 5-10 voltas espirais.

Comentários: espécie observada também na Baía de Paranaguá, Paraná, Sul do Brasil (observação pessoal).

Ocorrência nas amostras: Operação Sueste IV (estações 6607-6610, 6620-6621).

\section{Codonellopsis schabii (Brandt, 1906)} Figs $28,76,77$

Codonella morchella var. schabii Brandt, 1906, pl. 14, figs 5-6. Codonellopsis schabii; Kofoid \& Campbell, 1929: 87, fig. 157.Balech, 1959: 22, pl. 4, figs 65-67; pl. 5, figs 68-78.

Descrição: lórica aglutinante, partículas grosseiras, e formada por duas regiões: colar e corpo. Colar hialino composto por voltas espirais de lados paralelos; extremidade oral voltada para o exterior. Duas fenestras ocorrem na 4-6 volta, localizadas em lados simétricos. Corpo ovóide, extremidade anterior dilatada, formando os "ombros" (sensu Balech). Extremidade posterior acuminada.

Medidas (7 ind.): comp. 120-138 $\mu \mathrm{m}$; larg. 60-63 $\mu \mathrm{m}$; diâmetro oral 35-38 $\mu \mathrm{m}$; 9-12 voltas espirais.

Comentários: Para as sinonímias de espécies próximas, veja BALECH (1959).

Ocorrência nas amostras: Operação Sueste IV (estações 6607-6610, 6619-6621); Projeto COROAS (estações 1, 3, 5, 10). 


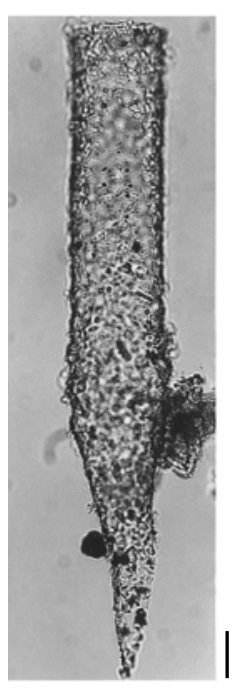

73
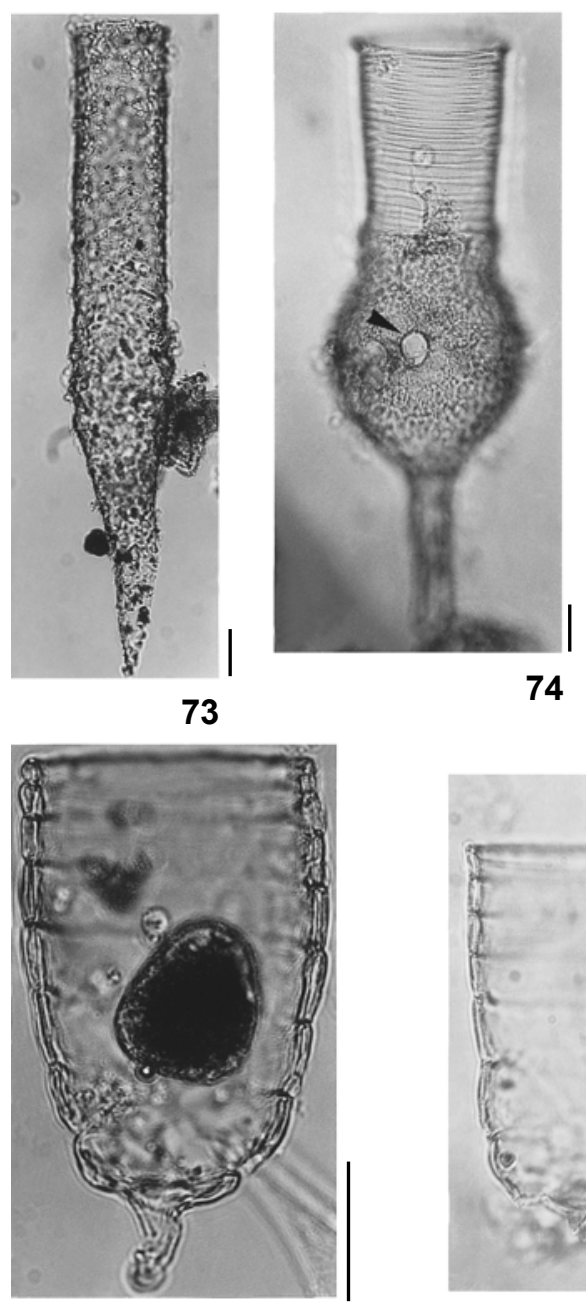

78

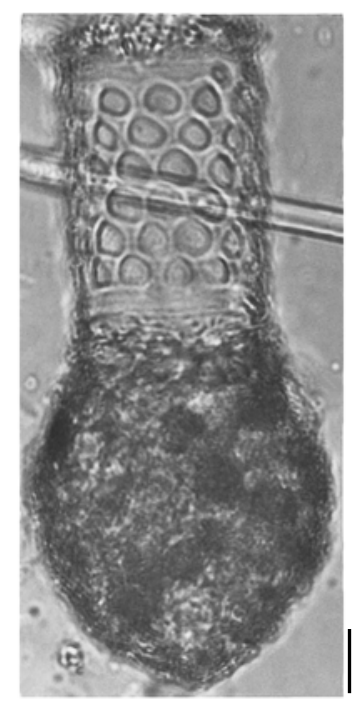

75
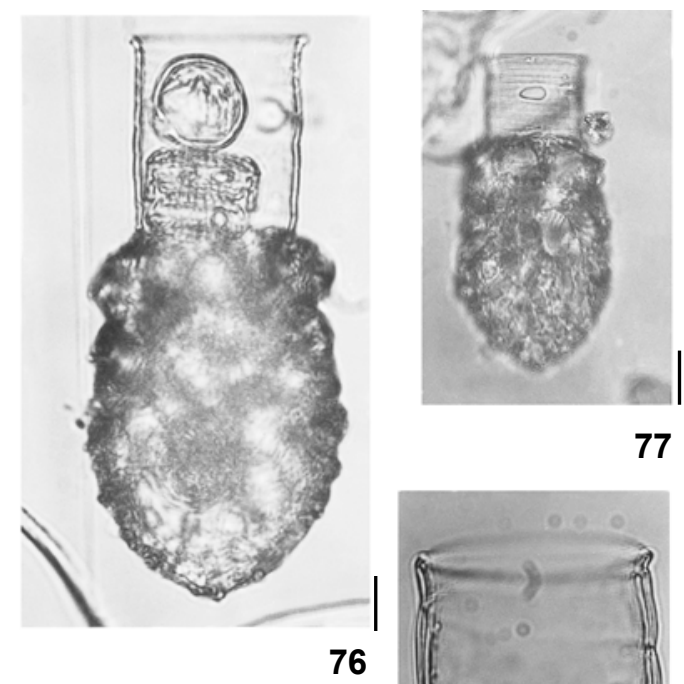

77

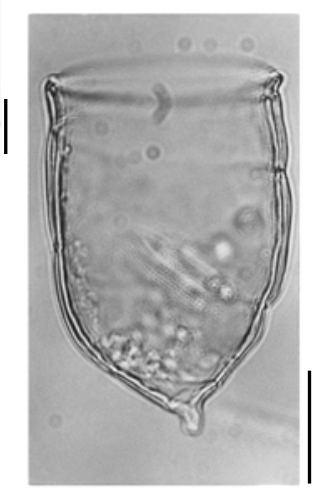

81
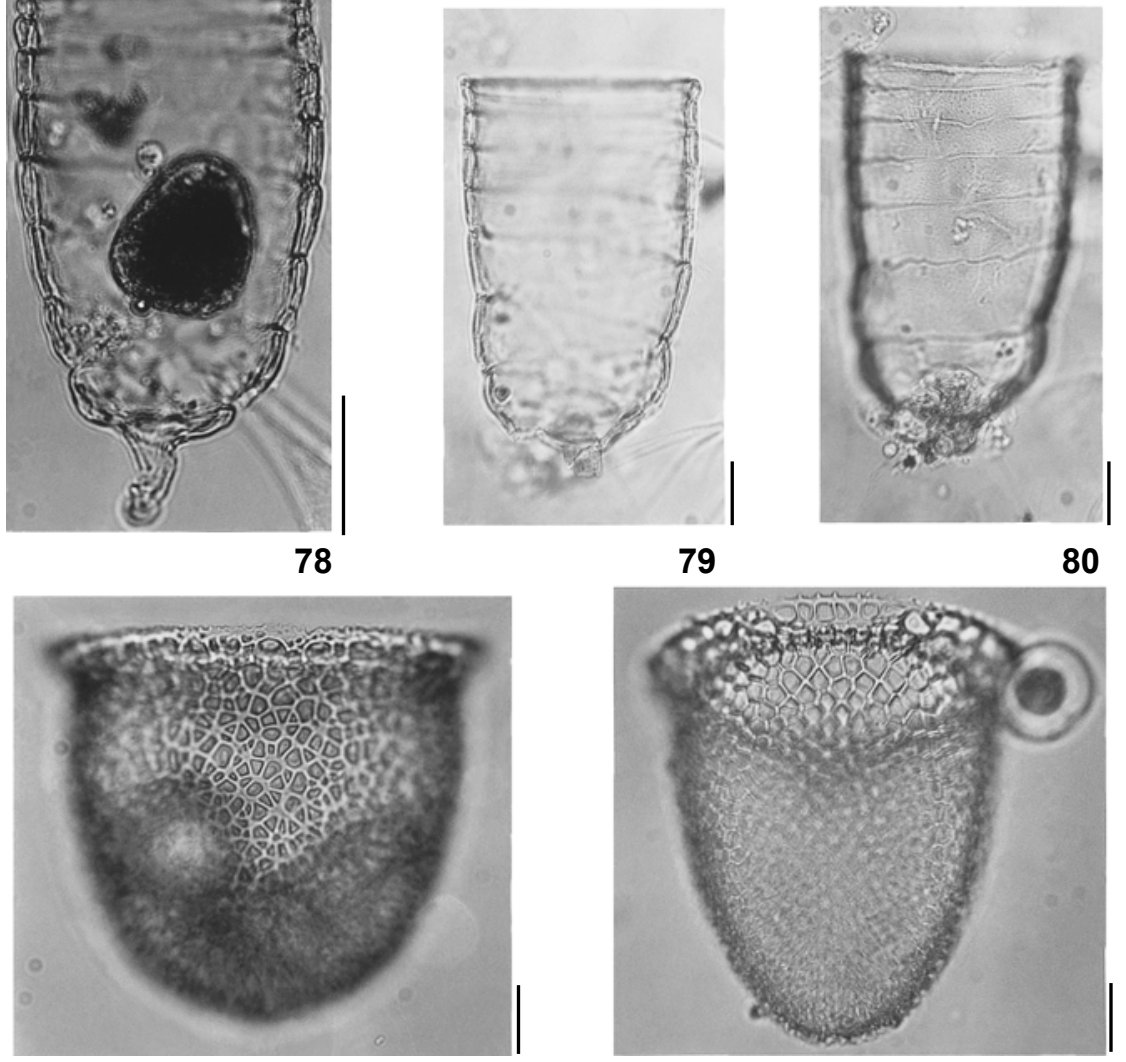

79

80

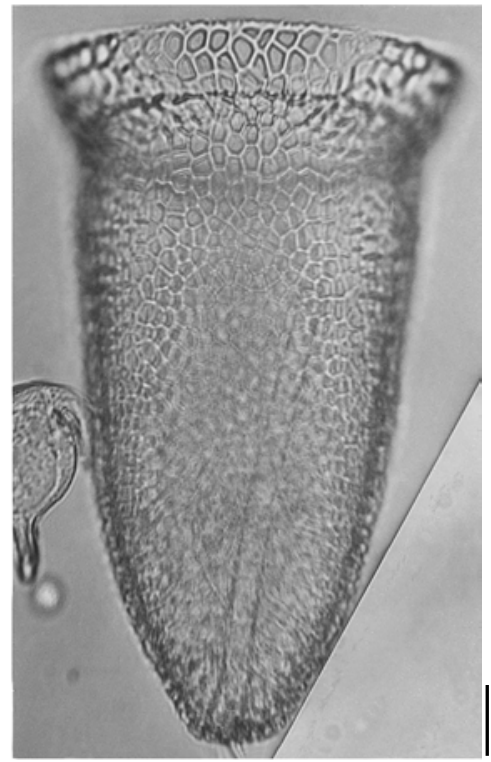

82

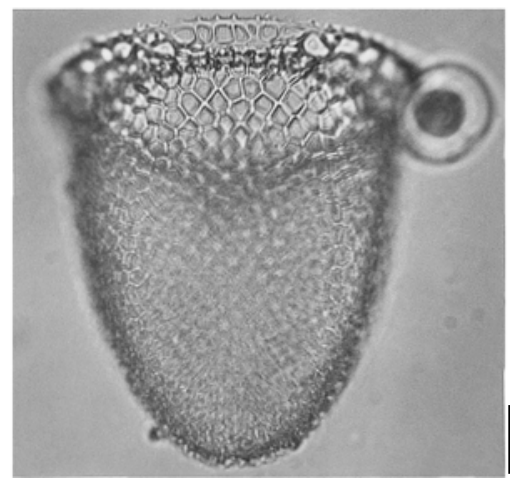

83

84

Figuras 73-84. (73) Tintinnopsis radix; (74) Codonellopsis orthoceras, a seta indica a janela; (75) Codonellopsis ostenfeldi; $(76,77)$ Codonellopsis schabii; $(78,81)$ Coxliella laciniosa; $(82,83)$ Cytarocylis brandtii; $(84)$ Cytarocylis conica. Barras de escala $=20 \mu \mathrm{m}$. 


\section{Coxliellidae Kofoid \& Campbell, 1929 Clymacocylis scalaria (Brandt, 1906)}

Cyttarocylis scalarius [sic] Brandt, 1906, pl. 21, fig. 15, pl. 26, figs 4-6, pl. 27, figs 1-3 (grafia original incorreta).- Brandt, 1907: 7. Clymacocylis scalaria; Jörgensen, 1924: 77, 105-106, fig. 88.Kofoid \& Campbell, 1929: 92-92, figs 185-188.

Descrição: lórica hialina cilíndrica, podendo terminar em uma região aboral cilíndrica ou como uma dilatação aboral semelhante a leque (Fig. 29). A parte cilíndrica da lórica é circundada por voltas espirais que se projetam para fora, formando um ângulo reto em relação ao cilindro. Superfície composta de uma única camada de alvéolos prismáticos hexagonais evidentes, exceto nas voltas espirais, compostas por 2-5 camadas irregulares. Cada alvéolo possui algumas aréolas delicadas dispersas em seu interior e nos lados. A extremidade aboral é assimétrica e aberta, podendo alongar-se para formar uma dilatação algo disforme, quase tubular até plana. Voltas espirais geralmente maiores na região aboral.

Medidas (12 ind.): comp. 278-351 $\mu \mathrm{m}$ (excluída a dilatação) e 325-401 $\mu \mathrm{m}$ (incluindo a dilatação); larg. máxima 45-55 $\mu \mathrm{m}$ (região central); larg. mínima 45-47 $\mu \mathrm{m}$; 18-26 voltas espirais (raramente 7-10 voltas).

Comentários: embora a espécie apresente dimensões consideráveis, é extremamente difícil de se detectar sua presença em amostras de plâncton devido sua transparência, o que pode explicar a ausência de registros para a região. KofoId \& CAMPBELL (1929), baseados no material de BRANDT (1907, como Cyttarocylis scalarius forma " $\mathrm{a}$ "), criaram a espécie Climacocylis scalaroides que, segundo eles, diferia de Climacocylis scalaria (ex Cyttarocylis scalarius Brandt) pelo menor tamanho, número inferior de voltas espirais e dilatação aboral menor. Entretanto, no presente trabalho, foram encontradas algumas lóricas transicionais entre C. scalaria e C. scalarius, o que levanta dúvidas sobre a validade destes táxons, ou seja, suas características não seriam suficientes para separar os dois táxons. Deste modo, a identificação original de BRANDT (1907), considerando as duas formas como variações da espécie Cyttarocylis scalarius (mais tarde transferida por Jörgensen (1924) para Climacocylis scalaria), seria a correta. As espécies Climacocylis elongata Kofoid \& Campbell (1929: 93, fig. 188), baseada em Brandt (1907: 19, pl.27, fig.1) e C. digitula Koford \& CAMPBell (1929: 92, fig. 186) podem ser consideradas sinonímia pelos mesmos motivos citados.

Ocorrência nas amostras: Espécie comum. Operação Monitor IV (estações 1-3, 6, 9/100 m, 12/10 m, 16-18, 27/10 m); Operação Sueste IV (estações 6599, 6601, 6603, 6604, 6606, 66106614, 6618, 6619); Projeto COROAS (estações 1, 3, 5, 7, 9, 10 , 13/150-100 m, 17/130-100 m).

\section{Climacocylis scalaroides Kofoid \& Campbell, 1929} Fig. 31

Climacocylis scalaroides Kofoid \& Campbell, 1929: 93, fig. 187. Descrição: lórica hialina tubular de lados paralelos, tor- nando-se convergentes no seu terço posterior. Extremidade oral irregular, ou seja, as paredes terminam em diferentes alturas. Região aboral fechada, provida de alvéolos irregulares pequenos ou grandes e grosseiros, formando um cone terminal. Cada alvéolo apresenta seu interior preenchido por fileiras de aréolas delicadas. Superfície da lórica constituída de uma única camada de alvéolos prismáticos hexagonais a quase esféricos. $\mathrm{Na}$ região oral, 3-4 voltas espirais circundam a superfície da lórica.

Medidas (2 ind.): comp. 196-205 $\mu \mathrm{m}$; larg. $38 \mu \mathrm{m} ; 3-4$ voltas espirais.

Ocorrência nas amostras: Operação Sueste IV (estações 66016604); Projeto COROAS (estações 13/150-100 m,19/130-70 m).

\section{Clymacocylis sipho (Brandt, 1906) Figs 32-33}

Cyttarocylis sipho Brandt, 1906, pl. 32, figs 8-8a, pl. 33, figs 55a.- Brandt, 1907: 21.

Clymacocylis sipho; Kofoid \& Campbell, 1929: 94, fig. 184.

Descrição: lórica hialina tubular alongada, lados paralelos no terço anterior a partir do qual tornam-se discretamente convergentes até a extremidade aboral aberta. Região oral provida de 16-20 voltas espirais, cada volta apresentando um número variável de dois tipos de janelas circulares: pequenas e agrupadas em fileiras horizontais de 3-6 janelas; ou grandes e separadas. Região mediana da lórica provida de superfície alveolada; alvéolos pouco evidentes e de tamanho e disposição variáveis, algumas áreas apresentando fileiras mais ordenadas de alvéolos pequenos, e outras com um número reduzido de grandes alvéolos. Região aboral constituída por alvéolos mais evidentes e unidos entre si, quadrangulares a subcirculares. Extremidade aboral assimétrica e aberta, em algumas lóricas apresentando um apêndice caudal alveolado (Fig. 33).

Medidas (3 ind.): comp. 230-260 $\mu \mathrm{m}$; larg. $47 \mu \mathrm{m}$; D.O. $47 \mu \mathrm{m}$; larg. mínima $23 \mu \mathrm{m}$; 16-20 voltas espirais.

Ocorrência nas amostras: Operação Sueste IV (estações 6603, 6604); Projeto COROAS (estações 1, 9).

\section{Coxliella fasciata (Kofoid, 1905) Brandt, 1906}

\section{Fig. 34}

Cyttarocylis fasciata Kofoid, 1905: 297-299, pl. 26, figs 6-7.

Coxliella fasciata; Brandt, 1906, pl. 28, figs 7, 9.- Brandt, 1907: 20.- Souto, 1970a: 195, figs 27-30.

Descrição: lórica hialina em forma de cone, lados discretamente convergentes até o terço posterior, quando se curvam para formar um apêndice caudal de extremidade quase aguda. Lâmina espiral composta de 14-16 espiras oblíquas evidentes, as de maior altura localizadas no encurvamento da lórica (região aboral). Parede formada por uma camada de alvéolos prismáticos hexagonais, mais visíveis próximo à região oral.

Medidas (5 ind.): comp. 234-263 $\mu \mathrm{m}$; larg. extremidade oral $69 \mu \mathrm{m}$; D.O. $65-66 \mu \mathrm{m}$; 14-16 voltas espirais.

Comentários: a escultura de pontos finos e a margem 
crenulada citadas por BALECH (1962) e Souto (1981) não foram observadas. Os exemplares de Souto (1970a) são menores

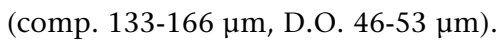

Ocorrência nas amostras: Operação Sueste IV (estações $6604,6614)$.

\section{Coxliella laciniosa (Brandt, 1907) Figs 35, 78-81}

Cyttarocylis (?) ampla var. laciniosa, Brandt, 1906, pl. 28, figs 12, 4 ; pl. 29.

Cyttarocylis (?) laciniosa var. a lata; Brandt, 1907: 271-272, 453. Coxliella laciniosa; Kofoid \& Campbell, 1929: 100, fig. 193.

Descrição: lórica hialina ogival, de lados convexos; extremidade aboral provida de apêndice caudal curto e arredondado. Lâmina espiral composta de espiras quase horizontais; espira da extremidade oral de menor tamanho que as demais. Parede finamente alveolada; alvéolos circulares; uma janela subcircular na segunda espira, contando-se a partir da extremidade aboral. A parede limitada por cada espira é quase reta e espessada.

Medidas (3 ind.): comp. 67-69 $\mu \mathrm{m}$; larg. extremidade oral $53 \mu \mathrm{m}$; D.O. $43 \mu \mathrm{m}$; 5-6 voltas espirais.

Comentários: algumas lóricas apresentaram paredes de lados paralelos a discretamente convergentes (Figs 78-79), com 5-8 voltas espirais e dimensões maiores (comp. 134,3-140,2 $\mu \mathrm{m}$, D.O. $68 \mu \mathrm{m}$ ). A lórica da Fig. 78 representa uma transição entre as formas de lados fortemente convexos e as de lados retos. Nas figuras 79-80 estão ilustradas duas lóricas que se afastam de C. laciniosa típica, pois as lâminas espirais são mais delgadas, não há janela, e o apêndice caudal é apenas incipiente.

Ocorrência nas amostras: Operação Sueste IV (estações 6604, 6614); Projeto COROAS (estações 1, 13/150-100 m).

\section{Cyttarocylidae Kofoid \& Campbell, 1929 Cyttarocylis brandti Kofoid \& Campbell, 1929} Figs $36,82-83$

Cyttarocylis plagiostoma; Brandt, 1906, pl. 35, fig. 7; pl. 36, figs 1, 6 (partim).- Brandt, 1907: 22.

Cyttarocylis brandti; Kofoid \& Campbell, 1929: 111, figs 215, fig. 217 (para C. longa).- Hada, 1938: 117, fig.33.

Descrição: lórica não aglutinante de cor marrom escuro quase negra, aproximadamente cônica de lados convexos, e semelhante a um elmo invertido (BALECH 1962); dividida em duas porções: colar e cesto, separados por uma pequena constrição. Colar cônico invertido projetado para fora; superfície provida de retículos subquadrangulares de diferentes tamanhos, maiores do que no cesto. Borda oral denticulada regularmente. Cesto cônico convexo, região aboral obtusa, com uma pequena elevação na extremidade aboral. Superfície reticulada irregularmente com alvéolos subquadrangulares a hexagonais, limitados entre si por traves de parede lisas.

Medidas (3 ind.): comp. 107-1125 $\mu \mathrm{m}$; larg. 94-94,8 $\mu \mathrm{m}$; D.O. $109 \mu \mathrm{m}$; altura do colar $13 \mu \mathrm{m}$.
Comentários: extremamente confusa a delimitação de espécies feita por Koford \& CAMPBElL (1929), baseada em características muito discretas de tamanho, morfologia e extremidade aboral (mais ou menos pronunciada). Diferenças entre as espécies próximas, segundo aqueles autores, são: 1) C. plagiostoma: cesto mais alargado e extremidade aboral aguda; maior espécie das três; 2) C. longa: cesto alargado, mas sem a pequena constrição lateral de C. brandti, extremidade aboral obtusa; 3) C. brandti: cesto mais longo e extremidade aboral obtusa.

Após análise detalhada das figuras de BRANDT (1907, pls $35 / 36$ ), as formas encontradas no presente trabalho ("C. brandti" $e$ "C. longa") foram identificadas como C. brandti. O mesmo procedimento foi seguido por HADA (1938: 117, fig.33). Apenas C. plagiostoma pareceu melhor delimitada por KOFOID \& CAMPBELL (1929).

Ocorrência nas amostras: Operação Sueste IV (estações 6604, 6614, 6615); Projeto COROAS (estações 1, 13/150-100 m, 17/130-100 m).

\section{Cyttarocylis conica (Brandt, 1906) \\ Fig. 84}

Cyttarocylis cassis var. conica Brandt, 1906, pl. 34, fig. 6, pl. 35, fig. 8.- Brandt, 1907: 21.

Cyttarocylis conica; Kofoid \& Campbell, 1929: 112, fig. 220.

Descrição: lórica hialina robusta composta por colar e cesto, separados por uma constrição pouco evidente. Colar bem menor do que o cesto e projetado para fora, formando um cone truncado invertido de lados paralelos. Borda oral provida de dentículos, com um discreto espessamento hialino. Parede reticulada, alvéolos poligonais grandes. Cesto em forma de cone alongado de lados convexos, extremidade aboral reta. Parede reticulada, alvéolos poligonais limitados por traves lisas evidentes, às vezes triangulares.

Medidas (3 ind.): comp. 187-192 $\mu \mathrm{m}$, D.O. 122,8 $\mu \mathrm{m}$.

Comentários: difere de C. cassis (Haeckel) Fol e $C$. acutiformis Kofoid \& Campbell, já citadas para o Oceano Atlântico Sul Ocidental (Souto 1981), devido à presença de extremidade aboral reta e lados do cesto convexos. As medidas de $C$. cassis também são menores do que as de C. conica.

Ocorrência nas amostras: Operação Sueste IV (estações 6604, 6614); Projeto COROAS (estações 1, 9/150-100 m).

\section{Epicancella nervosa (Cleve, 1900)} Figs 37, 37a, 85-87

Epiplocylis nervosa Cleve, 1900: 972, fig. 7.- Brandt, 1906, pl. 55, figs 4-7.- Brandt, 1907: 28.

Epicancella nervosa; Kofoid \& Campbell, 1939: 138, pl. 10, fig. 4.

Descrição: lórica hialina semelhante a cone de lados convexos e ligeiramente convergentes na região oral; extremidade aboral cuneada obtusa. Região oral provida de pequeno colar de parede quase reta, lisa, parcialmente encoberto por um anel 
suboral espessado e projetado para o exterior (Fig. 85), e provido de pontuações mais evidentes do que as do cesto. Entre o colar e o anel suboral forma-se um canal vazio. Superfície da lórica ornamentada de estruturas muito características: malha de costelas e pontuações subcirculares. A malha é constituída por 14-16 costelas verticais (ou discretamente diagonais), iniciando na região aboral ou ramificando-se de outra costela, até atingir o anel suboral, onde se tornam mais delgadas. Partindo das costelas verticais, uma série de costelas transversais a oblíquas (menos espessas) delimita áreas retangulares, em número de 12 a 16. Estas circundam pontuações delicadas e aproximadamente ordenadas em 5-6 fileiras por área. As pontuações são maiores e desordenadas no anel suboral, mais ou menos separadas em grupos pelas terminações das costelas verticais.

Medidas (7 ind.): comp. 81-86,9 $\mu \mathrm{m}$; larg. $55 \mu \mathrm{m}$; D.O. $46 \mu \mathrm{m}$; altura do colar 2,4-2,7 $\mu \mathrm{m}$; $14-16$ costelas verticais; costelas transversais a oblíquas (menos espessas) delimitando áreas retangulares em número de 12 a 16 .

Ocorrência nas amostras: Operação Monitor IV (estações 4/100 m, 10-11/100 m, 25/100 m); Operação Sueste IV (estação 6613); Projeto COROAS (estações 1, 7, 9/150-100 m; 1/ 200-0 m).

\section{Epiplocylis acuminata (Daday, 1887)}

\section{Figs 38,88}

Cyttarocylis acuminata Daday, 1887: 578-579, pl. 20, fig. 33. Epiplocylis acuminata; Jörgensen, 1924: 54, 56, 106, figs 63a63b.- Balech, 1959: 38, pl. 12, figs 185-197, pl. 13, figs 188190.- Souto 1970a: 197, fig. 33.

Descrição: lórica hialina caliciforme alargada; lados convergentes, mais acentuadamente na região aboral, terminando em extremidade aboral provida de apêndice caudal cônico, pontiagudo e curto. Região oral composta de parede fina com alvéolos (?) muito delicados; superfície interna da parede côncava; na superfície externa os lados são espessados e projetados para fora, formando uma borda de extremidade quase aguda, e atingindo o início da região mediana da lórica. Superfície na região mediana composta por alvéolos grosseiros, poligonais a quase circulares de lados convexos assimétricos, ou melhor, a altura do alvéolo é variável. Na região aboral os alvéolos tendem para a forma elíptica.

Medidas (8 ind.): comp. 80-85 $\mu \mathrm{m}$; larg. 49-58 $\mu \mathrm{m}$; D.O. 45-46 $\mu \mathrm{m}$; altura do colar $14 \mu \mathrm{m}$; apêndice caudal 14-17 $\mu \mathrm{m}$.

Comentários: O termo alvéolo deve ser melhor definido, uma vez que aqueles observados em outros gêneros (p. e., Codonaria e Codonella) parecem ser bem distintos dos alvéolos de Epiplocylis, característicos das espécies do gênero. BALECH (1959) incluiu E. carnegiei Campbell como sinônima de $E$. acuminata, entre outras.

Ocorrência nas amostras: Operação Sueste IV (estações 6604, 6617); Projeto COROAS (estações 1, 3, 5, 7, 9, 10, 17/130$100 \mathrm{~m}, 19 / 130-70 \mathrm{~m})$.

Revista Brasileira de Zoologia 21 (3): 551-576, setembro 2004

\section{Epiplocylis blanda Kofoid \& Campbell, 1939}

Fig. 39

Ptychocylis calyx var. a Brandt, 1906, pl. 58, figs 13, 13a.- Brandt, 1907: 292.- Hada, 1938: 127, fig. 44.- Kofoid \& Campbell; 1939: 127, pl. 8, fig. 5 .

Descrição: lórica hialina ogival de lados convexos, tornando-se convergentes na região aboral, e formando um apêndice caudal cônico curto de extremidade aguda. Superfície da lórica provida de dois tipos de alvéolos: grosseiros e evidentes, com apículos, ocorrendo desde a região aboral até a região oral, onde são substituídos por alvéolos delicados e pequenos, restritos à região oral. Próximo à região anterior da lórica, cristas longitudinais simples partem dos alvéolos grosseiros, estendendo-se para a região oral. As cristas também ocorrem nos alvéolos situados no apêndice caudal, prolongando-se até a sua extremidade. Estrutura da parede semelhante à de E. undella, descrita mais abaixo. Na borda oral a parede é delgada e não está diferenciada, ou seja, desprovida de ornamentações.

Medidas (4 ind.): comp. 81-85 $\mu \mathrm{m}$; larg. $49 \mu \mathrm{m}$; D.O. $45 \mu \mathrm{m}$; apêndice caudal $17 \mu \mathrm{m}$.

Comentários: espécie semelhante à E. undella, da qual difere pelas dimensões um pouco inferiores, maior desenvolvimento dos alvéolos e curvatura da parede da lórica. Difere de E. calyx (Brandt, 1906) Jörgensen, 1924 pela dimensão menor do D.O. (em E. calyx é $62 \mu \mathrm{m}$ ) e pela forma das paredes.

Ocorrência nas amostras: Operação Sueste IV (estações 6602-6604).

\section{Epiplocylis undella (Ostenfeld \& Schmidt, 1901)} Figs 40-41, 89-91

Cyttarocylis undella Ostenfeld \& Schmidt, 1901: 181, fig. 30. Epiplocylis undella; Jörgensen, 1924: 54-55, fig. 61.- Balech, 1962:

74, pl. 8, figs 83-92.- Souto, 1970a: 197, fig. 32.

Descrição: lórica hialina caliciforme de lados paralelos, tornando-se convergentes na região aboral, e formando um apêndice caudal cônico curto de lados retos e extremidade aguda. Superfície da lórica provida de dois tipos de alvéolos: delicados, pouco visíveis e unidos entre si, ocorrendo na região anterior até metade da lórica; e grosseiros e evidentes, ocorrendo em toda a região aboral. Próximo à região mediana da lórica, estes alvéolos apresentam prolongamentos como cristas (ou linhas ?) longitudinais, bifurcadas ou não, ocupando uma área de aproximadamente um quinto do comprimento da lórica. As cristas também ocorrem nos alvéolos situados no apêndice caudal, prolongando-se até a sua extremidade. Observando-se a parede por vista lateral (ou seja, pelos lados) na parte anterior não alveolada, é possível distinguir seu interior, composto de duas camadas que envolvem uma fileira de câmaras subretangulares transversais. Estas estruturas correspondem aos alvéolos delicados. Na porção posterior alveolada grosseiramente ocorrem pequenos apículos e ondulações dos 


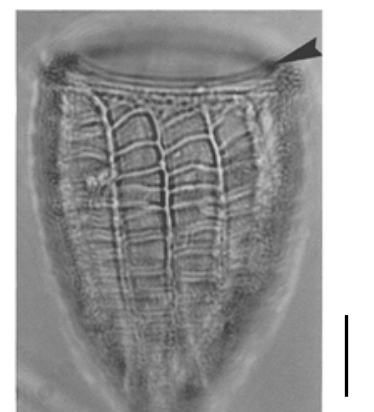

85

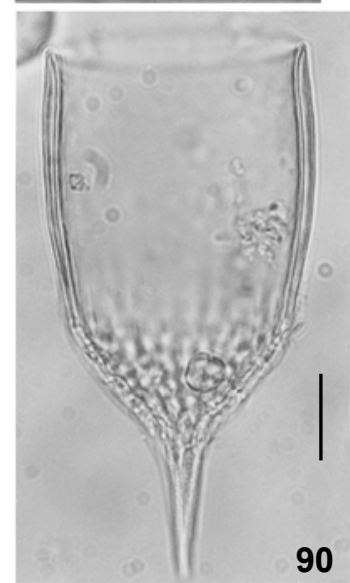

90
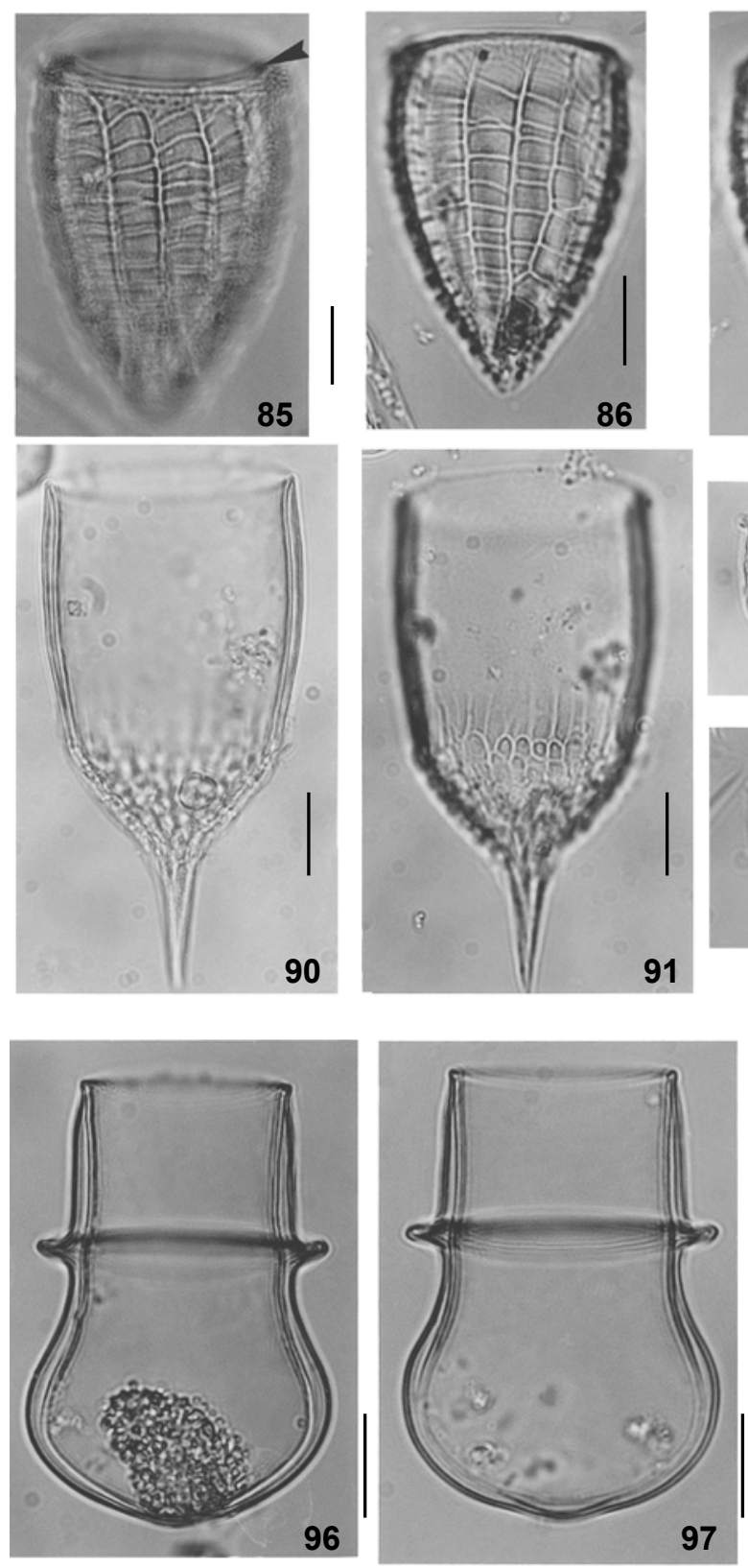

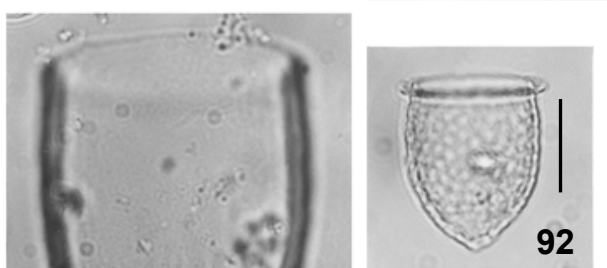

92

87

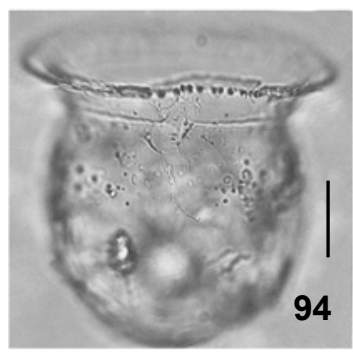

94

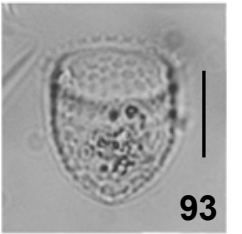

93

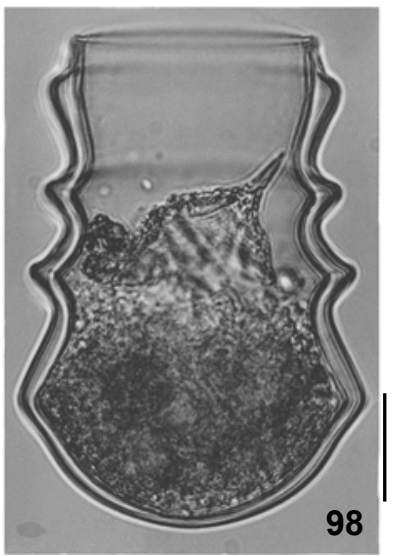

Figuras 85-100. $(85,87)$ Epicancella nervosa, a seta na figura 85 indica o colar; $(88)$ Epiplocylis acuminata; $(89,91)$ Epiplocylis undella; $(92,93)$ Achantostomella minutissima; $(94,95)$ Petalotricha ampulla; $(96,97)$ Amplectella monocollaria; $(98)$ Amplectella tricollaria; $(99$, 100) Undella claparedei. Barras de escala $=20 \mu \mathrm{m}$.

alvéolos e, aparentemente, não há estruturas como as da parte anterior da lórica. Na borda oral a parede é delgada e não está diferenciada, ou seja, desprovida de ornamentações.

Medidas (42 ind.): comp. 103-135 $\mu \mathrm{m}$; larg. $73 \mu \mathrm{m}$; D.O. $62 \mu \mathrm{m}$; apêndice caudal $19 \mu \mathrm{m}$.
Comentários: espécie bastante polimórfica, resultando na criação de várias espécies por KoFOID \& CAMPBELL (1929), com base em pequenos detalhes da forma e comprimento do apêndice caudal, da região alveolar e das linhas, a partir do material ilustrado por BRANDT (1907). As espécies são: E. atlantica, E. 
blanda, E. constricta, E. exquisita, E. impensa e E. pacifica. Posteriormente, BALECH (1962) encontrou várias formas com características intermediárias entre as espécies citadas. Após discutir os critérios de delimitação destas espécies e sua taxonomia, considerou-as todas sinonímias de E. undella. Finalmente, SASSI \& MeLo (1986) fornecem uma lista completa de sinonímias incluindo, entre outras, E. mucronata, E. pacifica e E. sargassensis. No presente trabalho seguimos os procedimentos dos autores citados.

Ocorrência nas amostras: Operação Monitor IV (estações14/10 m, 6, 9, 14/10 m, 21/10 m); Operação Sueste IV (estações 6599-6604, 6611, 6614, 6616-6619); PROANTAR XI (estações 2, 6, 7, 9); Projeto COROAS (estações 1, 3, 5, 7, 9, 10).

\section{Petalotrichidae Kofoid \& Campbell, 1929 Acanthostomella minutissima Kofoid \& Campbell, 1929 Figs $42-45,92-93$}

Acanthostomella minutissima Kofoid \& Campbell, 1929: 193, fig.358.- Kofoid \& Campbell, 1939: 145, pl. 11, figs 1, 4-6, 13 (partim).- Balech, 1968: 178, pl. 4, fig. 46.- Davis, 1985: 21-26.

Descrição: lórica hialina campanuliforme de lados paralelos a discretamente convergentes até a metade de sua extensão, convergindo na parte posterior e formando uma região aboral ogival. Extremidade aboral acuminada ou subaguda. Região oral provida de um colar liso circundado por uma plataforma que o sobrepassa. A borda da plataforma é expandida em dentículos triangulares regulares. Parede composta por alvéolos pentagonais e hexagonais conspícuos e com dimensões semelhantes, porém menores na região suboral. Algumas lóricas apresentaram alvéolos grandes na região aboral (Fig. 44).

Medidas (4 ind.): comp. 31-32,5 $\mu \mathrm{m}$, D.O. $23 \mu \mathrm{m}$, larg. 25,5-26 $\mu \mathrm{m}$.

Comentários: a espécie, descrita originalmente por KoFOID \& Campbell (1929), foi considerada sinônima de A. norvegica (Daday) Jörgensen por vários autores, conforme registrado em detalhe por DAvis (1985), mas nenhum deles ilustrou espécimes com alvéolos na parede da lórica. Davis argumentou sobre a clássica variação morfológica da lórica, como demonstrado por Laval-Peuto (1981) para Favella/Coxliella, mas cultivos com A. norvegica não foram realizados. Entretanto, a figura 1 (pl. 11) de KofoID \& CAMPBell (1939) mostra um indivíduo provido de alvéolos (como nas lóricas do presente trabalho) e que não ocorrem em A. norvegica, conforme pesquisado em vários trabalhos. Por este motivo, propomos manter o nome A. minutissima Kofoid \& Campbell para circunscrever exclusivamente a ilustração de Kofoid \& CAmpbell (1939) que, em nosso entender, seria uma espécie "boa". Repare ainda que BALEch (1968) e GaARDER (1946) ressaltam a presença de alvéolos, e Balech a considera uma espécie de "características mais definidas", inclusive suas dimensões.

Ocorrência nas amostras: Operação Monitor IV (estações 1-3, 22/10 m, 25/100 m); Operação Sueste IV (estações 6604, $6615,6617)$.

Revista Brasileira de Zoologia 21 (3): 551-576, setembro 2004

\section{Petalotricha ampulla (Fol, 1881) Figs 46 , 94-95}

Tintinnus ampulla Fol, 1881: 20-21, pl. 1, figs 1-3.

Petalotricha ampulla; Kent, 1882: 627, 629, figs 1-2.- Balech, 1959, pl. 12, figs 173-184.- Souto, 1970a: 201, fig. 45.

Descrição: lórica hialina esférica, dividida em cesto, colar e precolar. Cesto esférico com pequeníssimos alvéolos pouco evidentes recobrindo a parede, e janelas grandes em número variável podendo dispor-se em 1-2 fileiras longitudinais próximo ao centro do cesto. Extremidade aboral obtusa. Colar desenvolvido e projetado obliquamente com janelas elípticas de diferentes tamanhos; separado do cesto por uma constrição ampla.

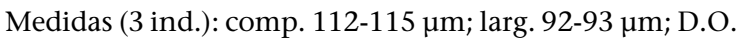
$107 \mu \mathrm{m}$.

Ocorrência nas amostras: Operação Sueste IV (estações 6602-6604); Projeto COROAS (estações 1, 3, 5, 7, 13/150-100 m, 17/130-100 m).

\section{Ptychocylidae Kofoid \& Campbell, 1929 Favella ehrenbergii (Claparéde \& Lachmann, 1858)} Fig. 47

Tintinnus Ehrenbergii Claparéde \& Lachmann, 1858: 203, pl. 8, figs 6-7.

Cyttarocylis ehrenbergii; Brandt, 1906, pl. 42, figs 2-4; pl. 61, fig. 9; Brandt, 1907: 24.

Favella ehrenbergii; Jörgensen, 1924: 8, 25-26, 28, 30-31.- Balech, 1959: 33, pl. 9, figs $146-149$, pl. 10, figs 150-153.- LavalPeuto, 1981: 249-272.- Sassi \& Melo, 1989: 63, pl. 2, figs 1015; pl. 3, figs 16-21; pl. 4, figs 22-24.

Descrição: lórica hialina em forma de sino com lados paralelos entre si, tornando-se cônico-convexos na região aboral. Esta apresenta um apêndice caudal afilado crestado e pouco regular, de ápice agudo. Parede da lórica bilamelar, superfície externa provida de reticulação delicada. Região oral com borda discretamente alargada encimada por colar provido de uma volta espiral, raramente mais (2-4).

Medidas (4 ind.): comp. 255-270 $\mu \mathrm{m}$; larg. 111-112 $\mu \mathrm{m}$ (borda oral); D.O. 108-109 $\mu \mathrm{m}$; uma volta espiral, raramente mais (2-4).

Comentários: Apenas lóricas de lados paralelos foram encontradas. As lóricas apresentam morfologia variável, levando a criação de vários taxa muito próximos. Para uma lista completa de sinônimos veja BALECH (1959), KofoId \& CAMPBELL (1929) e Sassi \& Melo (1989). Laval-Peuto (1981) demonstrou a existência de morfótipos distintos durante o ciclo vital de $F$. ehrenbergii, incuindo as formas "annulata" e "decipiens" que correspondem às espécies Coxliella annulata e C. decipiens.

Ocorrência nas amostras: Operação Sueste IV (estações $6596,6608,6609,6610,6619,6621)$. 


\section{Poroecus curtus Kofoid \& Campbell, 1929 Figs 48-49}

Poroecus curtus Kofoid \& Campbell, 1929: 118, fig. 224.- Balech, 1968: 172, pl. 2, fig. 10.

Descrição: lórica hialina cilíndrica até o terço posterior, quando se torna cônica de lados convergentes convexos a retos e forma um apêndice caudal cônico curto de extremidade obtusa. É comum um dos lados do apêndice ser ligeiramente côncavo e o outro convexo ou reto, conferindo um aspecto assimétrico à lórica. Extremidade oral lisa e regular, ou às vezes irregular devido à presença de campos poligonais; geralmente apresenta uma inflexão de lados convexos. Parede evidente e constituída de dois tipos de reticulação: prismas primários delicados e campos secundários poligonais a subcirculares, aproximadamente de mesmo tamanho. Estes podem apresentar dois tipos de disposição na lórica: desordenada com campos um pouco maiores na região oral; ou ordenados na região oral em fileiras transversais de campos subretangulares, e o restante da lórica com campos poligonais desordenados. Os prismas delicados são visualizados ao redor dos campos poligonais.

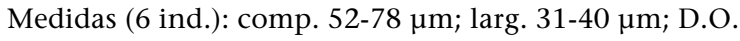
30-40 $\mu \mathrm{m}$.

Comentários: os termos utilizados foram baseados em Kofoid \& CAMpbell (1939).

Ocorrência nas amostras: Operação Sueste IV (estações 6614-6616, 6603); Projeto COROAS (estações 1, 9/150-100 m); PROANTAR XI (estação 9).

\section{Tintinnididae Kofoid \& Campbell, 1929 Leprotintinnus nordqvistii (Brandt, 1906) Kofoid \& Campbell, 1929 \\ Figs 50-51}

Tintinnopsis nordqvistii Brandt, 1906, pl. 24, figs 1-4; Brandt, 1907: 4.

Leprotintinnus nordqvistii; Kofoid \& Campbell, 1929: 17, fig. 13.Hada, 1938: 91, fig. 3.- Sassi \& Melo, 1982: 145, pl. 1, fig. 1.

Descrição: lórica aglutinante cilíndrica até a região aboral, quando a parede se expande para formar uma dilatação semelhante á cone truncado bastante dilatado de margem irregular, podendo estar reduzido em algumas lóricas (Fig. 50). Borda oral irregular, não dilatada. Lórica revestida por sedimentos finos a grosseiros.

Medidas (4 ind.): comp. 154-215 $\mu \mathrm{m}$, D.O. 38-39 $\mu \mathrm{m}$, diâmetro aboral 45-75 $\mu \mathrm{m}$.

Comentários: lóricas maiores do que as encontradas por SASSI \& Melo (1982). Nenhuma citação foi encontrada para o Brasil, exceto a de SASSI \& Melo (1989) para o Nordeste (estado da Paraíba). BarRía del CAO (1986) registrou uma lórica em Bahia Blanca, Argentina.

Ocorrência nas amostras: Operação Sueste IV (estações $6620,6621)$

\section{Undellidae Kofoid \& Campbell, 1929 Amplectella monocollaria (Laackmann, 1910) Figs 96-97}

Undella monocollaria Laackmann, 1910: 470, pl. 49, fig. 20.

Amplectella monocollaria; Kofoid \& Campbell, 1929: 253, fig. 489.- Souto, 1970a: 201, fig. 46.- Balech, 1975: 397, pl. 2, fig. 56.

Descrição: lórica hialina robusta de lados paralelos até pouco mais da metade de sua extensão, quando se tornam divergentes e convexos, formando um cesto alargado. Próximo à região mediana da lórica ocorre um anel projetado de parede espessada que, em vista lateral, é triangular. Parede da lórica lisa e espessa, exceto na extremidade oral, onde é delgada. Extremidade aboral obtusa, às vezes discretamente acuminada.

Medidas (4 ind.): comp. 102,7-104 $\mu \mathrm{m}$; D.O. $43 \mu \mathrm{m}$; larg. 65-66 $\mu \mathrm{m}$

Comentários: medidas inferiores àquelas encontradas por Balech (1975) e Souto (1970a), onde o comprimento da lórica é bem maior do que no presente trabalho.

Ocorrência nas amostras: Operação Sueste IV (estações 6602-6604, 6612); Projeto COROAS (estações 1, 3, 7, 13/150$100 \mathrm{~m}, 17 / 130-100 \mathrm{~m})$.

\section{Amplectella tricollaria (Laackmann, 1910) Fig. 98}

Undella tricollaria Laackmann, 1910: 470, pl. 49, figs 18-19. Undellopsis tricollaria; Kofoid \& Campbell, 1929: 272, fig. 522. Amplectella tricollaria; Balech, 1975: 394, pl. 2, fig. 60.

Descrição: lórica hialina, robusta, composta por um cilindro anterior e um cesto. Cilindro maior do que o cesto e provido de três anéis projetados para o exterior. Cada anel em vista lateral é triangular, de base côncava. $\mathrm{O}$ anel mais próximo à extremidade oral (lisa) é menos pronunciado e de concavidade mais suave. Cesto de lados retos divergentes em sua metade anterior, tornando-se convergentes e convexos para formar uma extremidade aboral obtusa. Parede da lórica lisa e espessada, mais delgada nas regiões oral e aboral.

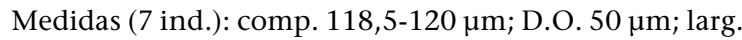
$80 \mu \mathrm{m}$.

Ocorrência nas amostras: Operação Sueste IV (estações 6602-6604, 6614); Projeto COROAS (estações 1, 9, 19/150-100 m).

\section{Undella claparedei (Entz, Sr., 1885)} Figs $99-100$

Tintinnus claparèdii [sic] Entz, Sr., 1885: 202-203, pl. 14, figs 10-11.

Undella claparedei; Daday, 1887: 179, pl. 19, fig. 1.- Balech, 1975: 383, pl. 1, figs 29-35.

Descrição: lórica ovóide provida de constrição suboral mais ou menos conspícua, resultado do espessamento interno da parede. Extremidade oral lisa, circular. Extremidade aboral 
obtusa até pontiaguda ou acuminada. Algumas lóricas podem apresentar parte externa da parede modificada para formar ângulos, originando uma aparência poligonal (Fig. 100). Parede espessada, particularmente na região suboral, decrescendo em direção à região aboral.

Medidas (4 ind.): comp. 64-75 $\mu \mathrm{m}$; larg. 52-63 $\mu \mathrm{m}$; D.O. 38-46 $\mu \mathrm{m}$; espessamento suboral 4-5 $\mu \mathrm{m}$.

Comentários: BALECH (1975) comenta que, em alguns casos, pode-se observar uma estrutura alveolar muito discreta na parede. Distingue-se das demais espécies (como U. perpusilla (Kofoid \& Campbell) Balech) por seu comprimento e largura maiores e pelo D.O. superior a $33 \mu \mathrm{m}$. Para lista completa de sinonímias, consulte BALECH (1975).

Ocorrência nas amostras: Operação Sueste IV (estações 6602-6604, 6613, 6615-6617); Projeto COROAS (estações 1, 3, 13/150-100 m, 17/130-100 m).

\section{Undella globosa Brandt, 1906}

Fig. 52

Undella claparedei var. globosa Brandt, 1906, pl. 64, fig. 34. Undella globosa; Balech, 1975: 385, pl. 1, figs 38-39.

Descrição: lórica hialina globosa até saculiforme, parede espessada, sempre abrangendo toda a região aboral, espessamento suboral presente e projetando-se para o exterior da lórica. Extremidade aboral obtusa.

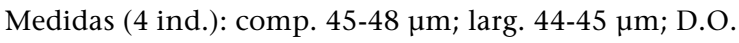
$27 \mu \mathrm{m}$.

Comentários: Difere de U. claparedei por suas dimensões e D.O. menores, pelo espessamento suboral projetado tanto para o exterior como para o interior da lórica, e pela forma globosa.

Ocorrência nas amostras: Operação Monitor IV (estações12-13/100 m); Operação Sueste IV (estações 6604, 6615); Projeto COROAS (estações 1, 3, 17/130-100 m); PROANTAR XI (estação 10).

\section{Undella hyalina Daday, 1887 Figs $53,101-103$}

Undella hyalina Daday, 1887: 159-208, pl. 1, fig. 7.- Brandt, 1906, pl. 63, figs 1-6; pl. 64, figs 17-19.- Brandt, 1907: 30/31.Balech, 1975: 378, pl. 1, fig. 7.

Descrição: lórica hialina grande, cilíndrica. Lados paralelos, ou apresentando uma dilatação discreta na região aboral (ou de morfologia variável, Figs 99-101). Extremidade aboral obtusa, ás vezes um pouco projetada. Parede trilaminar evidente, abrangendo toda a lórica. A região suboral pode ou não apresentar uma dilatação discreta, projetada para fora.

Medidas (15 ind.): comp. 145-228 $\mu \mathrm{m}$; larg. 48-53 $\mu \mathrm{m}$; D.O. $47-49 \mu \mathrm{m}$.

Comentários: para lista completa de sinonímias, consulte BALECH (1975).

Ocorrência nas amostras: Operação Monitor IV (estação 3/100 m, 26/10 m); Operação Sueste IV (estações 6599, 6602-
6604, 6612-6616); Projeto COROAS (estações 1, 3, 7, 9, 13/ 150-100 m, 17/130-100 m).

\section{Undella lachmanni Daday, 1887 Figs 55,55 a}

Undella lachmanni Daday, 1887: 568.- Balech 1975: 380, lâm. I, fig. 15 .

Descrição: lórica hialina de lados convexos, tornando-se retos na região aboral, e formando uma extremidade aboral pronunciada e aguda. Extremidade oral reta e lisa. Parede evidente e constituída por estrutura trilaminar, sem espessamento na região suboral. Na extremidade oral a parede apresenta-se delgada.

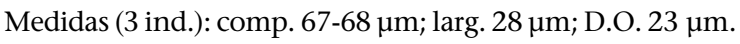

Comentários: Suas dimensões a aproximam mais dos exemplares de U. lachmanni Daday encontrados por BALECH (1975) (comp. 72-87 $\mu \mathrm{m}$; D.O. 27,0-27,5 $\mu \mathrm{m}$ ), mas estes apresentam parede de lados paralelos até metade da lórica. Outras espécies de morfologia semelhante são $U$. grandis (Laackmann) (comp. 95-100 $\mu \mathrm{m}$, D.O. $45 \mu \mathrm{m}$ ) e U. cuspidata (Kofoid \& Campbell) (comp. 80-106 $\mu \mathrm{m}$, D.O. 34-43 $\mu \mathrm{m}$ ), mas ambas com dimensões maiores e espessamento suboral conspícuo.

Ocorrência nas amostras: Operação Sueste IV (estações $6604,6614)$.

\section{Undella perpusilla (Kofoid \& Campbell, 1929) Fig. 54}

Proplectella perpusilla Kofoid \& Campbell, 1929: 281, fig. 524. Undella perpusilla; Balech, 1975: 389, pl. 1, figs 40-42.

Descrição: lórica hialina de lados convexos e extremidade aboral obtusa. Parede espessada até a região aboral, e apenas mais discretamente mais delgada nesta do que na região oral. Região suboral dilatada para a parte interna da lórica.

Medidas ( 2 ind.): comp. 63-65 $\mu \mathrm{m}$; larg. $42 \mu \mathrm{m}$; D.O. $30 \mu \mathrm{m}$.

Comentários: embora as medidas encontradas sejam mai-

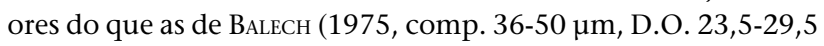
$\mu \mathrm{m})$, sua morfologia é semelhante. Espécie muito semelhante à algumas lóricas de $U$. claparedei, diferindo desta pelas dimensões e pelo estreitamento evidente da parede na região aboral.

Ocorrência nas amostras: Operação Monitor IV (estações 9/10 m, 14/100 m); Projeto COROAS (estações 1, 9/150-100 m)

\section{Undella pistillum Kofoid \& Campbell, 1929 Figs $56,56 a$}

Undella pistillum Kofoid \& Campbell, 1929: 265, fig. 500.Balech, 1975: 380, pl. 1, fig. 8.

Descrição: lórica hialina semelhante a vaso de lados paralelos e fundo chato. Na região oral os lados são convergentes, tornando-se paralelos até a região aboral, quando se curvam para formar uma extremidade aboral quase plana. Espessamento da parede evidente, delgado na extremidade oral e mais pronunciado na região oral. Superfície recoberta por estriação delicada, aparentemente composta de pequeníssimos 


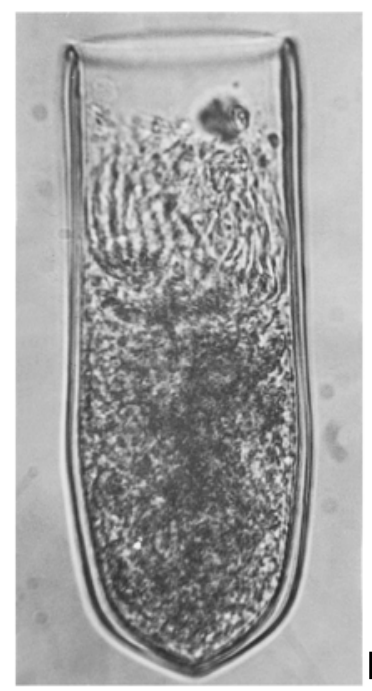

101
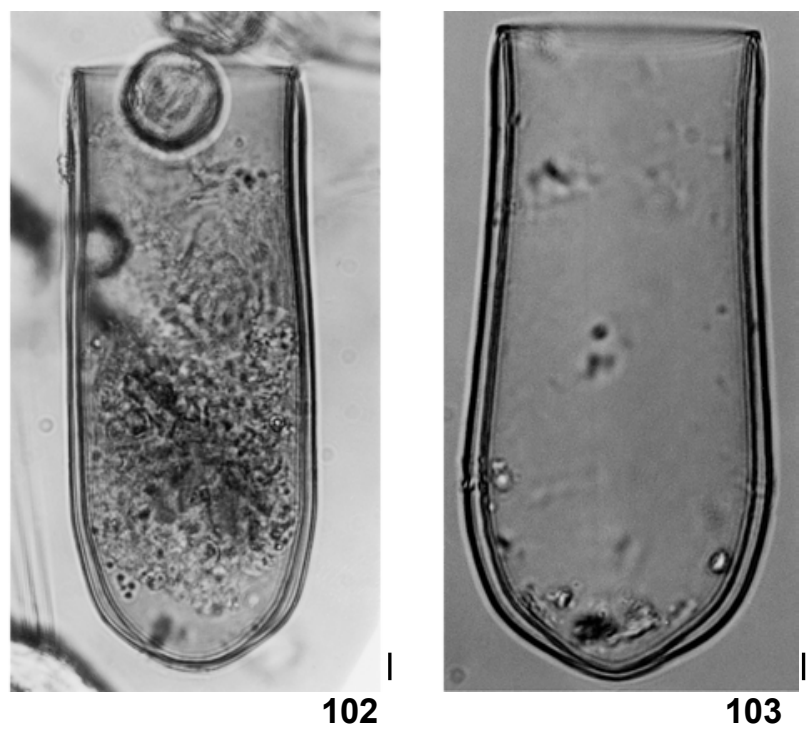

Figuras 101-103. Undella hyalina. Barras de escala $=20 \mu \mathrm{m}$.

pontos; estrias curvas ordenadas obliquamente em grupos que se cruzam entre si. A parede é dividida em três seções: lâmina externa, câmaras intermediárias retangulares transversais, e lâmina interna, revestindo o interior da lórica (Fig. 56a).

Medidas ( 2 ind.): comp. 87-88 $\mu \mathrm{m}$; larg. $55 \mu \mathrm{m}$; D.O. 43 $\mu \mathrm{m} ; 10-11$ estrias em $10 \mu \mathrm{m}$ no espessamento da parede.

Comentários: as medidas de D.O. indicadas em BALECH (1975) e Kofold \& CAMPBell (1929) são um pouco menores (36$40 \mu \mathrm{m}$ ), e a morfologia da lórica algo diferente, particularmente na região aboral, mais dilatada do que nas lóricas encontradas no presente trabalho.

Ocorrência nas amostras: Projeto COROAS (estação 1); PROANTAR XI (estação 11).

\section{Undella subacuta Cleve, 1900}

Fig. 57

Undella subacuta Cleve, 1900: 923, fig. 4a- Balech, 1975: 382, pl. 1, fig. 16; Balech \& Souto, 1981: 44, pl. 4, fig. 10. Proplectella subacuta; Kofoid \& Campbell, 1929: 282, fig. 543.

Descrição: lórica hialina de lados discretamente divergentes até a região aboral, onde formam uma dilatação evidente. Região aboral em forma de cone truncado invertido de lados ligeiramente convexos, extremidade aboral subaguda.

Medidas (1 ind.): comp. $68 \mu \mathrm{m}$; larg. $47 \mu \mathrm{m}$; D.O. $32 \mu \mathrm{m}$.

Comentários: espécie de morfologia semelhante àquela ilustrada por BALECH (1975), mas suas medidas são menores

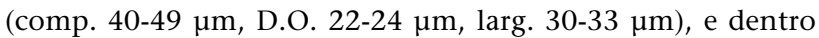
dos limites de $U$. subcaudata acuta.

Ocorrência nas amostras: Operação Monitor IV (estação 10/100 m); Operação Sueste IV (estação 6611); Projeto COROAS (estações 1, 7, 9/150-100 m).

\section{Undella subcaudata acuta (Jörgensen, 1924) Figs 58, 58a}

Undella subacuta f. acuta Jörgensen, 1924: 39-41, fig. 43a. Undella subcaudata acuta; Balech, 1975: 383, pl. 1, fig. 23.

Descrição: lórica hialina de lados convexos e extremidade aboral aguda. Extremidade oral reta e lisa. Parede evidente e constituída por estrutura trilaminar, espessada na região suboral, formando um estrangulamento na área interna da lórica, e estendendo-se até a extremidade aboral. Esta região apresenta-se cônica de ápice agudo.

Medidas (3 ind.): comp. $65 \mu \mathrm{m}$; larg. $36 \mu \mathrm{m}$; D.O. $26 \mu \mathrm{m}$.

Comentários: semelhante á $U$. grandis, mas com dimensões menores (BALECH 1975), e à Undella ellipsoida Kofoid \& Campbell, da qual difere pelas medidas ligeiramente menores (KoFoID \& CAMPBell 1929). A lórica da figura 53 apresenta morfologia bastante semelhante às figuras 8 e 9 de BALECH \& Souto (1981), exceto pela discreta constrição na região oral, ausente em nossos espécimes; e é idêntica à ilustrada em BALECH (1975).

Ocorrência nas amostras: Operação Monitor IV (estação 10/100 m); Projeto COROAS (estações 13/150-100 m, 17/130$100 \mathrm{~m})$.

\section{AGRADECIMENTOS}

Á Diretoria de Hidrografia e Navegação e às tripulações dos NOcs. "Almirante Saldanha" e "Barão de Teffé", pelo empenho em integrar biólogos e militares, e auxílio durante as coletas. A iniciativa da DHN em cooperar com pesquisadores e embarcá-los em navios hidrográficos contribuiu significativamente para o desenvolvimento da pesquisa em oceanografia biológica no Brasil e, no tocante a este trabalho, para o conhecimento da taxonomia dos tintininos. Ao Dr. Roberto Sassi/ 
NEPREMAR, UFPB, pelas sugestões e correções do manuscrito. Aos professores MsC. João Roberto Maceno-Silva (CEM/UFPR), Dr. Salvador A. Gaeta (IO/USP, coordenador do Projeto COROAS) e MsC. Mayza Pompeu (IO/USP), que gentilmente cederam as amostras de plâncton de rede e dados físicos e químicos referentes à Op. Sueste IV e ao Projeto COROAS. Financiado pelo Curso de Pós-graduação em Zoologia, UFPR/CNPq (bolsa L.F.F.) e Centro de Estudos do Mar, UFPR. Ao Dr. Olaf Mielke (Departamento de Zoologia, UFPR) o qual forneceu orientações valiosas sobre nomenclatura zoológica a um botânico de formação. Este trabalho é parte da Tese de Doutorado no Curso de Pós-graduação em Ciências Biológicas, Zoologia, UFPR.

\section{REFERÊNCIAS BIBLIOGRÁFICAS}

Alder, V.A. 1999. Tintinnoinea, p. 321-384. In: D. Boltovskoy (Ed.). South Atlantic Zooplankton. Leiden, Backhuys Publishers, vol. 1, 868p.

Bakker, C. \& W. Phaff. 1976. Tintinnida from coastal waters of the S.W. Netherlands. I. The genus Tintinnopsis Stein. Hydrobiologia, Kiel, 50 (2): 101-111.

BALECH, E. 1948. Tintinnoinea de Atlantida (R.O. del Uruguay) (Protozoa-Ciliata-Oligotrichida). Comunicaciones del Museo Argentino de Ciencias Naturales «Bernardino Rivadavia», Serie C, Zoología, Buenos Aires, 7:1-23.

- 1959. Tintinnoinea del Mediterraneo. Trabajos del Instituto Espanhol de Oeanografia, Madrid, 28: 1-88.

- 1962. Plancton de las campañas oceanograficas Drake I y II. Servicio de Hidrografia Naval, Buenos Aires, H.627: 1-57.

-1968. Algunas especies nuevas o interessantes de tintinidos del Golfo de México y Caribe. Revista del Museo Argentino de Ciencias Naturales «Bernardino Rivadavia», Hidrobiología, Buenos Aires, 2 (5): 164-197.

. 1971. Microplancton de la campaña oceanográfica Productividad III. Revista del Museo Argentino de Ciencias Naturales «Bernardino Rivadavia», Hidrobiología, Buenos Aires, 3 (1): 1-202.

- 1972. Los tintinidos indicadores de afloramiento de águas (Ciliata). Physis, Buenos Aires, 31 (83): 519-528.

- 1975. La Família Undellidae (Protozoa - Ciliata, Tintinnina). Physis, Buenos Aires, 34 (89): 377-398.

BALECH, E. \& S. Souto. 1980. Los tintininos de la campaña oceanografica "Productividad" IV. Parte I. Physis, Buenos Aires, 39: 1-8.

- 1981. Los tintininos de la campaña oceanografica "Productividad" IV. Parte II. Physis, Buenos Aires, 39: 41-49.

Barría del CaO, M.S. 1986. Contribución al conocimiento de Tintinnina (Protozoa, Ciliophora) de la zona de Bahía Blanca, II (Argentina). Boletín del Instituto Español de Oceanografía, Madrid, 3: 143-150.

Bernard, C. \& F. Rassoulzadegam. 1993. The role of picoplankton (Cyanobacteria and plastidic picoflagellates) in the diet of tintinnids. Journal of Plankton Research, Oxford 15: 361-373.
Biedermann, R. 1893. Ueber der Tintinnen-Gehäuse. Kiel, Inauguralis Dissertatio, 38p.

Brandt, K. 1906. Die Tintinnodeen der Plankton-Expedition. Tafelerklärungen kuerzer Diagnose der neuen Arten. Ergebnisse der Atlantik Plankton-Expedition, Bremen, 3 (L.a.), 33p.

. 1907. Die Tintinnodeen der Plankton-Expedition. Systematischer Teil. Ergebnisse der Atlantik PlanktonExpedition, Bremen, 3 (L.a.): 1-499.

Bresslau, E. 1906. Eine Anzahl Tintinnen aus dem Plankton der Bucht von Rio de Janeiro. Verhandlungen der Deustschen Zoologischen Gesellschaft, Leipzig, 16: 260-261.

Campbell, A.S. 1942. The oceanic Tintinnoina of the plankton gathered during the last cruise of the Carnegie. Scient. Res. Cruise VII Carnegie during 1928-1929 under the command of Captain J. P. Ault. Carnegie Institute Washington Publications, Washington, (537): 1-162.

Choi, J.K.; D.W. Coats, D.C. Brownlee \& E.B. Small. 1992. Morphology and infraciliature of three species of Eutintinnus (Ciliophora, Tintinnina) with guidelines for interpreting protargol-stained tintinnina ciliates. Journal of Protozoology, Bristol, 39 (1): 80-92.

Claparéde, E, \& Laackmann, J. 1858. Études sur les infusoires et les rhizopodes. Memoire des Institute Genevois, Paris et Genéve, 5 (3): 1-260.

Cleve, P. T. 1900. Some Atlantic Tintinnodea. Kongliga Svenska Vetenskaps Akademies Handlingar, Stockholm, 56: 969975.

Cunha, A.M. \& O. Fonseca. 1918. O microplancton das costas meridionaes do Brazil. Memórias do Instituto Oswaldo Cruz, Rio de Janeiro, 10 (2): 99-103.

DaDAY, E. 1887. Monographie der Familie der Tintinnoideen. Mittheillungen Zoological Statione Neapel, Budapest, 7: 1-172.

DAvis, C. 1985. A comparison of the zooplankton in two Newfoundland bays with differing influences from major currents. Internal Revue gesbricht Hydrobiologie, Kiel, 71 (1): 11-47.

DHN. 1987. CXIX Comissão oceanográfica. Operação Sueste IV. Costa Sueste - oceanografia física, química e biológica. Rio de Janeiro, Marinha do Brasil, 22p.

. 1989. CXLI Comissão oceanográfica. Operação Monitor IV. Costa Sul - oceanografia física, química e biológica. Rio de Janeiro, Marinha do Brasil, 22p.

Dodson, A.N. \& W.H. Thomas. 1978. Reverse filtration, p. 104107. In: A. Sournia (Ed.). Phytoplankton manual. Monographs on oceanographic methodology 6. Paris, UNESCO, 300p.

EnTZ, Sr., G. 1885. Zur näheren der Tintinnoden. Mittheillungen Zoological Statione Neapel, Budapest, 6: 185-216.

FARIA, J.G. \& A.M. CunHA. 1917. Estudos sobre o microplancton da Baía do Rio de Janeiro e suas imediações. Memórias do Instituto Oswaldo Cruz, Rio de Janeiro, 9 (1): 68-93. 
Fernandes, L.F. 1999. Tintininos (Protozoa-Ciliophora-Subordem Tintinnina) de águas subantárticas e antárticas entre a Argentina e a Península Antártica $\left(35^{\circ} \mathrm{S}-62^{\circ} \mathrm{S}\right)$ (Novembro de 1992). Revista Brasileira de Oceanografia, São Paulo, 47 (2): 155-171.

- 2004. Tintininos (Ciliophora, Tintinnina) de águas subtropicais na região Sueste-Sul do Brasil. II. Famílias Dictyocystidae, Rhabdonellidae, Tintinnidae e Xystonellidae. Revista Brasileira de Zoologia, Curitiba, 21 (3): 605628.

Fernandes, L.F. \& F.P. Brandini. 1999. Comunidades microplanctônicas no Oceano Atlântico Sul Ocidental: biomassa e distribuição em novembro de 1992. Revista Brasileira de Oceanografia, São Paulo, 47 (2): 189-205.

Fol, 1881. Contribution a la connaissance de la famille des Tintinnoidea. Archives des Sciences Physiques et Natureles, Genebra, 3 (5): 5-24.

. 1884. Sur la famille des Tintinnoidea. Recueil Zoologie Suisse, Genebra, 1: 27-64.

GaARDER, K.R. 1946. Tintinnoinea from the "Michael Sars" North Atlantic deep-sea expedition 1910. Reports of the Scientific Research "Michael Sars" North Atlantic deep-sea expedition, 1910, Florida, 2 (1): 1-37.

Garrison, D.L. \& M.M. Gowing. 1993. Protozooplankton, p.123165. In: E.I. Friedmann (Ed.). Antarctic microbiology. London, Wiley-Liss, 800p.

HADA, Y. 1938. Studies on the Tintinnoinea from the Western Tropical Pacific. Journal of the Faculty of Sciences Hokkaido Imperial University, Series VI, Zoology, Hokkaido, 6 (2): 87-190.

HAECKEL, E. 1873. Ueber einige neue pelagische Infusirien. Jenaische Zeitschrift für Naturwissenschaft, Jena, 7: 561568.

IMNHOF, O. E. 1886. Ueber microscopische pelagische Thiere aus den Lagunen von Venedig. Zoologischer Anzeiger, Leipzig, 9: 101-104.

Jörgensen, E. 1912. Bericht über die von der schwedischen Hydrographisch Biologischen Kommision in den schwedischen Gewässern in den Jahren 1909-1910 eigesammelten Planktonproben. Skrifter Schwedischen HydrographischBiologischen Kommision, Kiel, 4: 1-20.

- 1924. Mediterranean Tintinnidae. Report of Danish Oceanographic Expedition 1908-1910 to the Mediterranean and adjacent seas, Kopenhagen, 2: 1-114.

JefFrey, S.W. \& G.F Humphrey. 1975. New spectrophotometric equations for determining chlorophylls a,b,c, and c1 in higher plants, algae and natural phytoplankton. Biochemie Physiologen Pflanzen, Sttutgart, 167: 191-194.

Kent, W.S. 1882. A manual of the Infusoria. London, Bogue, 2 vols, atlas, $\mathrm{X}+913 \mathrm{p}$.

Koford, C.A. 1905. Some new Tintinnidae from the plankton of the San Diego region. University of California Publications in Zoology, Los Angeles, 1: 287-306.
Kofoid, C.A. \& A.S. Campbell. 1929. A conspectus of the marine and freshwater Ciliata belonging to the suborder Tintinnoinea, with descriptions of new species principally from the Agassiz Expedition to the Eastern tropical Pacific, 19041905. University of California Publications in Zoology, Los Angeles, 34: 1-403.

- 1939. Reports on the scientific results of the expedition to the Eastern tropical Pacific, in charge to Alexander Agassiz, by U.S. Fish commision steamer "Albatross", from October, 1904, to March, 1905, Lieut.-Commander L.M. Garrett, U.S.N. commanding. XXXVII. The Ciliata: The Tintinnoinea. Bulletin of the Museum of Comparative Zoology of Harvard College, Harvard, 85: 1-473.

LaAckmann, H. 1910. Die Tintinnodeen der deutschen Südpolarexpedition 1901-1903. Deutsche Südpolar- expedition, Berlin, 11: 340-496.

Laval-Peuto, M. 1981. Construction of the lorica in Ciliata Tintinnina. In vivo study of Favella ehrenbergii: variability of the phenotypes during the cycle, biology, statistics, and biometry. Protistologica, Paris, 17 (2): 249-272.

. 1982. Methods of taxonomy and selection for determination of marine planktonic Protozoa. Annales des Institute oceanographique des Paris, Paris, 58 (5): 151-168.

Laval-Peuto, M. \& D.C. Brownlee. 1986. Identification and systematics of the Tintinnina (Ciliophora): evaluation and suggestions for improvement. Annales des Institute oceanographique des Paris, Paris, 62 (1): 69-84.

Levine, N.D.; J.O. Corliss; F.E.G. Cox; G. Deroux; J. Grain; B.M. Honiberg; G.F. Leedale; A.R.III Loeblich; J. Lom; D. Lynn; E.G. Merinfeld; F.C. Page; G. Poljansky; V. Sprague; J. Vavra \& F.G. WALLACE. 1980. A newly revised classification of the Protozoa. Journal of Protozoology, Sttutgart, 27 (1): 37-58.

LoHmann, H. 1908. Utersuschungen zur Feststellung des vollständigen Gehalts des Meeres an Plankton. Wissenschaftliche Mittheilungen, Kiel, 10: 129-370.

Lynn, D.H. \& D.J.S. Montagnes. 1991. Global production of heterotrophic marine planktonic ciliates, p. 281-307. In: P. C. Reid; C. M. Turley \& P. H. Burkill (Eds). Protozoa and their role in marine processes. New York, Springer Verlag/ NATO, ASI Ser., V. G25, 600p.

Marshall, S.M. 1969. Protozoa: Order Tintinnida. In: J.H. Fraser $\&$ K. HANSEN (Eds). Fiches d'identification du zooplancton. No.117-127. Charlottenlund, Conseil Permanent international des Exploracion de Mer, Paris.

Ostenfeld, C.H. \& J. Schmidt. 1901. Plankton fra det Röde Hav og Adenbugten. Videnskabelige Meddelelser fra den Natur Historiske Forening i Kjöbenkavn, Kopenhagen, 1901, p.141-182.

Pierce, R.W. \& J.T. Turner. 1992. Ecology of planktonic ciliates in marine food webs. Review in Aquatic Sciences, Florida, 6: 139-181.

1993. Global biogeography of marine tintinnids. Marine Ecology Progressive Series, Kiel, 94:11-26. 
SASSI, R. \& G.N. MeLo. 1982. Contribuição ao conhecimento da fauna de protozoários do estuário do rio Mandacaru. Revista Nordestina de Biologia, João Pessoa, 5 (2): 141-155. . 1986. Tintinnina (Protozoa - Ciliophora - Oligotrichida) from the first brazilian expedition to the Antartic. Anais Academia Brasileira de Ciências, Rio de Janeiro, 58 (Supl.): 63-83.

- 1989. Hyaline Tintinnina (Protozoa - Ciliophora Oligotrichida) from northeastern brazilian coastal reefs. Boletim do Instituto Oceanográfico de S. Paulo, São Paulo, 37 (1): 59-74.

SAssi, R.; M.B.B. Kutner \& M. Pompeu. 1999. First record of the ciliate Eutintinnus apertus with attached diatom Chaetoceros tetrastichon in neritic waters of Southwestern Atlantic. Revista Nordestina de Zoologia, Recife, 13 (1/2): 10-15.

Schmid, J. 1901. Some Tintinnodea from the Gulf of Siam. Videnskabellige Meddeleljer fra den Natur Historiske Forening i Kjobenhaun, 1901, Kopenhagen, p.183-190.

SHerR, B.F.; E.B. SHERr \& C.S. Hopkinson. 1986. Trophic interactions within pelagic microbial communities: indications of feedback regulation of carbon flow. Hydrobiologia, Sttutgart, 159: 19-26.

Sniezeck, J.H.; G.M. Capriulo; E.B. Small \& A. Russo. 1991. Nolaclusilis hudsonicus sp. nov., a bilaterally symmetric tintinnine ciliate from the Lower Hudson river estuary. Journal of Protozoology, Bristol, 38: 589-594.

Snyder, R.A. \& D.C. Brownlee. 1991. Nolaclusilis bicornis n.g., sp. nov. (Tintinnida: Tintinnididae): a tintinnine ciliate with novel lorica and cell morphology of Chesapeake Bay estuary. Journal of Protozoology, Bristol, 38: 583-589.

Sousa E SILVA, E.S. 1952. Tintinnoinea das águas litorais da Guiné portuguesa. Boletim Cultural da Guiné Portuguesa, Lisboa, 7 (27): 607-623.

Souto, S. 1970. Tintinidos de la costa atlántica entre los $31^{\circ} \mathrm{y}$ $35^{\circ}$ de latitud Sur (Uruguay y Sur de Brasil). Physis, Buenos Aires, 30: 187-208.

. 1970a. Tintinidos de la costa brasilera colectados por el Walther Herwig. Physis, Buenos Aires, 30: 209-224.

. 1981. Tintinnina, p. 303-381. In: D. Boltovskoy (Ed.).

Atlas del Zooplancton del Atlântico Sudoccidental y metodos de trabajo con el zooplancton marino. Mar del Plata, Publ. esp. INIDEP, 1000p.

Stoecker, D.K. \& J.M. Capuzzo. 1990. Predation on Protozoa: its importance to zooplankton. Jounal of Plankton Research, Oxford, 12: 891-908.

Strickland, J.D.H. \& T.R. Parsons. 1972. A practical handbook of seawater analysis. 2nd. ed.. Bulletin of Fisheries Research Board Canada, Quebec, 122: 1-172.

Thompson, G.A.; V.A. Alder; D. Boltovskoy \& F.P. Brandini. 1999. Abundance and biogeography of tintinnids (Ciliophora) and associated microplankton in the Southwestern Atlantic Ocean. Journal of Plankton Research, Oxford 21 (7): 12651298.

Uribe, E. \& J. Castillo. 1982. Tintinnidos indicadores de masas de agua. Investigaciones Marinas, Valparaíso, 10 (1-2): 1534 .

Recebido em 11.VI.2003; aceito em 26.VII.2004. 